\title{
Silver oxide nanostructure prepared on porous silicon for optoelectronic application
}

\author{
Marwa Abdul Muhsien Hassan • Ibrahim Ramdan Agool • \\ Lamyaa Mohammed Raoof
}

Received: 21 February 2013/Accepted: 16 March 2013/Published online: 20 April 2013

(c) The Author(s) 2013. This article is published with open access at Springerlink.com

\begin{abstract}
The thermal evaporation system type (Edwards) has been used to evaporate high purity (99.9\%) silver on glass, $n$ - and $p$-type silicon and porous silicon substrates at room temperature under low pressure (about $10^{-6}$ torr) for different thickness $(50,75,100,125$ and $150 \mathrm{~nm})$. Using a rapid thermal oxidation of $\mathrm{Ag}$ film at oxidation temperature $350{ }^{\circ} \mathrm{C}$ and different oxidation times, $\mathrm{Ag}_{2} \mathrm{O}$ thin film was prepared. The structural properties of $\mathrm{Ag}_{2} \mathrm{O}$ film were investigated and compared with other published results. The structural investigation showed that the films formed at thickness $100 \mathrm{~nm}$ showed (111) strong reflection along with weak reflections of (101) corresponding to the growth of single phase $\mathrm{Ag}_{2} \mathrm{O}$ with cubic structure. Dark and illuminated $I-V$ of $p-\mathrm{Ag}_{2} \mathrm{O} / p-\mathrm{Si}, p-\mathrm{Ag}_{2} \mathrm{O} / n-\mathrm{Si}, \mathrm{Al} / p-\mathrm{PSi} / \mathrm{Al}$, $\mathrm{Al} / n-\mathrm{PSi} / \mathrm{Al}, \quad p-\mathrm{Ag}_{2} \mathrm{O} / p-\mathrm{PSi} / \mathrm{c}-\mathrm{Si}$ and $p-\mathrm{Ag}_{2} \mathrm{O} / n-\mathrm{PSi} / \mathrm{c}-\mathrm{Si}$ heterojunction were investigated, discussed and prepared at optimum condition (oxidation temperature $350{ }^{\circ} \mathrm{C}$ and $90 \mathrm{~s}$ oxidation time with thickness $100 \mathrm{~nm}$ ). Ohmic contacts were fabricated by evaporating 99.999 purity silver wires for back and aluminum wires for front contact, respectively.
\end{abstract}

Keywords $\mathrm{Ag}_{2} \mathrm{O} \cdot$ Rapid thermal oxidation - AFM . $\mathrm{SEM} \cdot p-\mathrm{Ag}_{2} \mathrm{O} / \mathrm{PSi} / \mathrm{c}-\mathrm{Si} \cdot$ Photovoltage properties

\section{Introduction}

Silver oxide $\left(\mathrm{Ag}_{2} \mathrm{O}\right)$ is conventionally used as electrode materials in batteries or as catalytic substances in materials

M. A. M. Hassan $(\bowtie)$ - I. R. Agool · L. M. Raoof

Department of Physics, College of Science, Al-Mustansiriyah

University, Baghdad, Iraq

e-mail: marwa_alganaby@yahoo.com science. Yet, there are also studies showing that thin films of $\mathrm{Ag}_{2} \mathrm{O}$ exhibit semiconducting properties. Various techniques had been used in preparing thin films of $\mathrm{Ag}_{2} \mathrm{O}$, including sputtering or evaporation of $\mathrm{Ag}$ ( $\mathrm{or} \mathrm{Ag}_{2} \mathrm{O}$ ) in an oxygen atmosphere, and oxidation of $\mathrm{Ag}$ films with reactive oxygen species, such as oxygen plasma, oxygen radicals, ozone, etc. Previous investigations of electronic structures and optical properties of $\mathrm{Ag}_{2} \mathrm{O}$ films reveal that $\mathrm{Ag}_{2} \mathrm{O}$ has a band gap of $\sim 1.3 \mathrm{eV}$, and an ionization potential of $\sim 1.0 \mathrm{eV}$ below the work function of $\mathrm{Ag}$ (i.e., $\sim 5.3 \mathrm{eV}) . \mathrm{Ag}_{2} \mathrm{O}$ films in general were reported to show $p$-type semiconducting properties with the Fermi level ranging from 4.8 to $5.1 \mathrm{eV}$ (Chen et al. 2003). Silver oxide is transparent in infrared and visible range due to its large optical band gap. This property is useful to make antireflective coating for applications in the opt-electrical field (Peyser et al. 2001). Silver oxide $\left(\mathrm{Ag}_{2} \mathrm{O}\right)$ films have received increasing attention due to their unique properties (Hou et al. 1998). As a battery electrode, $\mathrm{Ag}_{2} \mathrm{O}$ may achieve better performance in voltage regulation with a longer storage life (Passaniti and Megahed 1995; Smith et al. 1997). Büchel et al. (2001) and Tominaga (2003) reported that $\mathrm{Ag}_{2} \mathrm{O}$ films could be used as surfaceenhanced Raman spectroscopy sources due to the surfaceplasmon effect. In addition, $\mathrm{Ag}_{2} \mathrm{O}$ films, a typical wide energy gap semiconductor, have a reflectivity higher than $70 \%$ over a wide wavelength range, with the advantage of being applicable in short-wavelength optical data storage to replace the commonly used organic storage material. Tominaga et al. (1992) first suggested that $\mathrm{Ag}_{2} \mathrm{O}$ films can be used as the storage material of CD-R instead of the commonly used organic material. Using $\operatorname{Ag}_{2} \mathrm{O}$ film not only raises the short wavelength storage density of CD-R but also enhances their signal-to-noise ratio. The development of the super-resolution near-field technique has 
made super density storage possible by breaking through the resolution limit and reducing spot size. In Refs. (Tominaga et al. 1998; Fukaya et al. 1999; Cai and Wei 2000), the authors have made satisfactory progress in this area. Fuji et al. (2000) pointed out that the $\mathrm{Ag}_{2} \mathrm{O}$ film could be used as a readout layer to produce a metallic probe as a non-transparent aperture where the near-field light is produced. Peyser et al. (2001) reported a strong photoactivated emission of nanoscale $\mathrm{Ag}_{2} \mathrm{O}$ structures after subjecting the film to $515 \mathrm{~nm}$ irradiation. Zhang et al. (2003) found the dynamically activated fluorescence emission of $\mathrm{Ag}_{2} \mathrm{O}$ films. These results confirm that $\mathrm{Ag}_{2} \mathrm{O}$ films could be used as a nanoscale optical storage material. Subsequently, Chiu et al. (2003) and Kim et al. (2001) reported that the $\mathrm{Ag}_{2} \mathrm{O}$ film could be used as a mask layer to enhance the magneto-optical signal of new magnetooptical disks. Silver oxide thin films are a very interesting class of metal oxides; silver being a multivalent, forms various phases like $\mathrm{Ag}_{2} \mathrm{O}, \mathrm{AgO}, \mathrm{Ag}_{3} \mathrm{O}_{4}$ and $\mathrm{Ag}_{2} \mathrm{O}_{3}$ by interacting with oxygen. Experimentally, it is found that $\mathrm{Ag}_{2} \mathrm{O}$ and $\mathrm{AgO}$ are the most observable phases (Ravi Chandra Raju 2011).

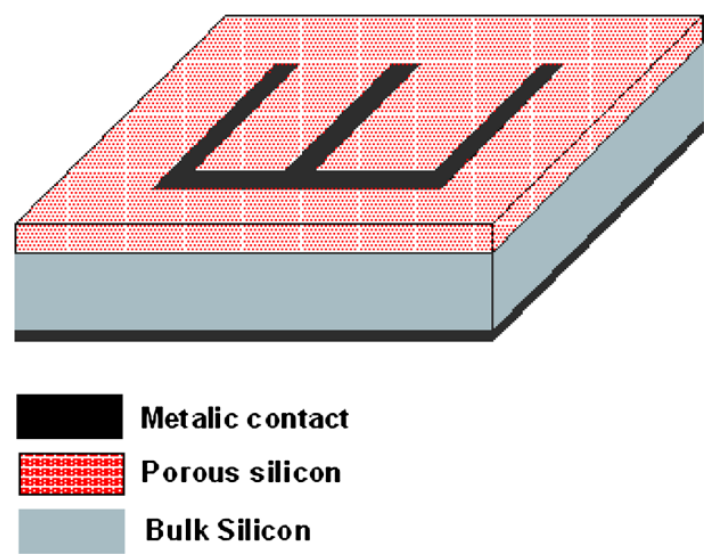

Fig. 1 Porous silicon-based photodiode (Guerrero-Lemus et al. 1999)
It is well known that a porous silicon (PSi) layer can be formed on one side of a crystalline silicon wafer (c-Si) by an electrochemical etching process. The morphology of the PSi layer depends on the c-Si conductivity type and etching conditions basically. It has been shown that the $p$-type PSi ( $p$-PSi) layer has distributed micro- and nanopores (so named because of the pore size), whereas an $n$-type PSi (n-PSi) usually contains macropores and a rough surface (Arenas et al. 2006). Due to the small size of the silicon structures in the PSi layers, the quantum effect (Arenas et al. 2008) is observed: the forbidden band gap $\left(E_{\mathrm{g}}\right)$ energy value of a PSi layer is greater than that of the c-Si, in spite of the discrepancies in the classification according to whether the PSi electronic transition are indirect (Sagnes et al. 1993; Lugo and del Rio 1998) or direct (Feng and Tsu 1994). PSi has many unique characteristics such as direct and wide modulated energy band gap, high resistivity, vast surface area to volume ratio and the same single crystal structure as bulk silicon. Those advantages make it a suitable material for photodetector (Smestad and Kunst 1992). On the other hand, a few studies on PSi for photovoltaic application have been reported. Photovoltaic is a

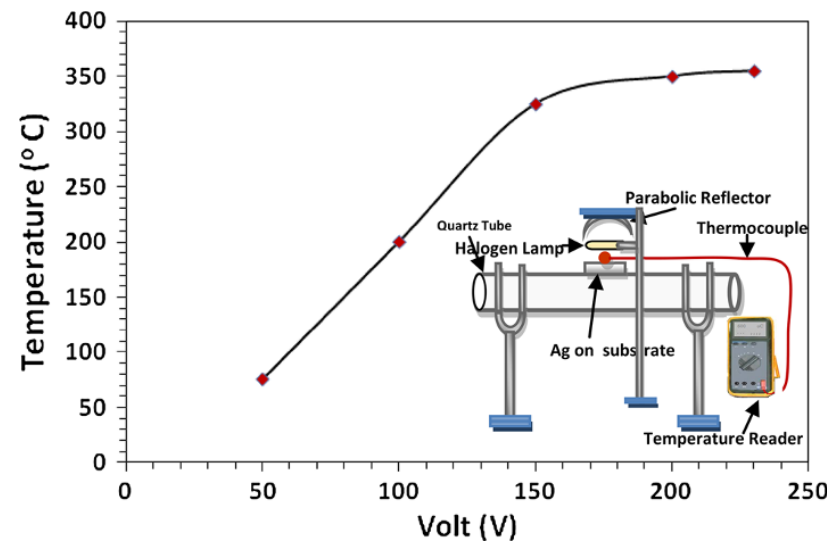

Fig. 3 Scheme for the calibration system, rapid thermal oxidation
Fig. 2 a Electrochemical etching cell set-up and b photoelectrochemical etching (PECE) cell set-up (a)

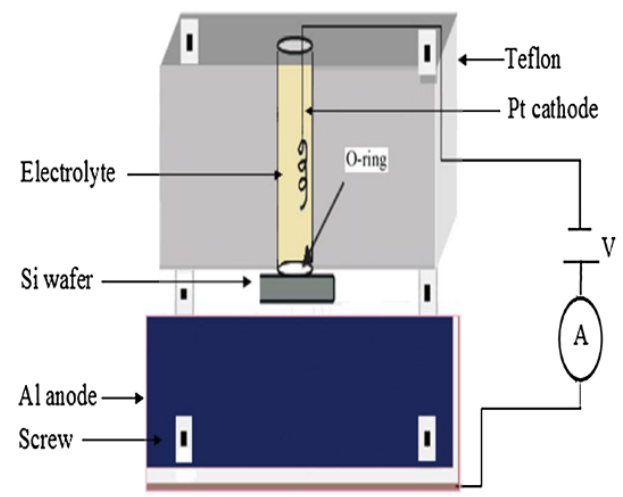

(b)

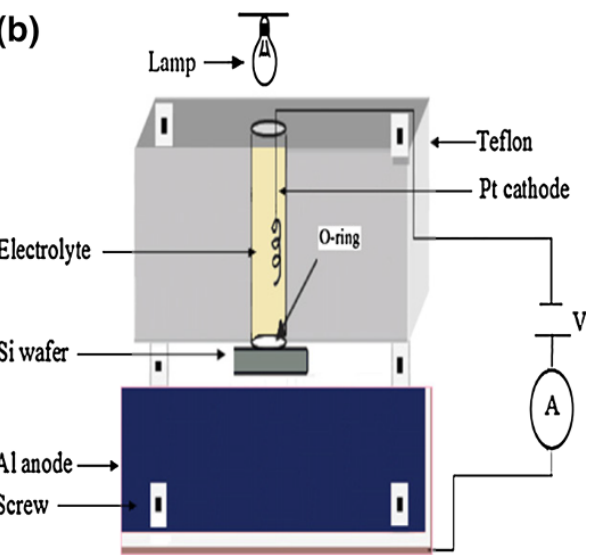


renewable energy, which is helpful to reduce the pollution and climate change effects. Today, photovoltaic industry is dominated by silicon solar cells technology because of the reduced cost. It is basic material for the production of solar cell and about $90 \%$ of fabricated solar modules are made of crystalline silicon. For solar cells, PSi layer acts as an ultra efficient anti-reflection coating, while a graded layer with varying expanded band gap offers an increased absorption in visible spectrum regions (Foss 2005). Potential advantages of using PSi in solar cell structures include highly textured morphology of PSi that may be

Table 1 Coefficient determined for the empirical Eq. (7)

\begin{tabular}{lll}
\hline HF concentration $(\%)$ & $\mathrm{K}\left(\mathrm{cm}^{3} / \mathrm{mA} \mathrm{s}\right)$ & $m$ \\
\hline 30 & $1.01 \times 10^{-7}$ & 0.98 \\
40 & $1.05 \times 10^{-7}$ & 0.96 \\
50 & $1.13 \times 10^{-7}$ & 0.92 \\
\hline
\end{tabular}

used to enhance light trapping, and due to its adjustable band gap for optimum sunlight absorption (Kaidashev et al. 2003) and due to the simplicity of the fabrication so, solar cell incorporating PSi can be achieved at low cost (Kasap 2002). The two most common PSi diode structures reported were contact $_{1} / \mathrm{PSi} / \mathrm{Si} /$ contact $_{2}$ and contact $_{1} / \mathrm{PSi} /$ contact $_{2}$, where contact $_{2}$ may have been the same as contact $_{1}$ which was usually a metal or conducting oxide. PSi diodes usually exhibit current density $(J)$ versus voltage $(V)$ characteristics which are asymmetric with the polarity of the applied voltage, i.e. current rectification is observed. As a consequence, PS diodes have been analyzed in terms of the two most familiar types of rectifying diodes: the Schottky barrier and the $p-n$ junction (Canham 1997). The basic structure of these devices is $\mathrm{Al} / \mathrm{PSi} / \mathrm{c}-\mathrm{Si} / \mathrm{Al}$. This structure is modified by adding semitransparent conducting films (Al) onto the external surface of the PSi layer, as shown in Fig. 1 (Guerrero-Lemus et al. 1999). (a)

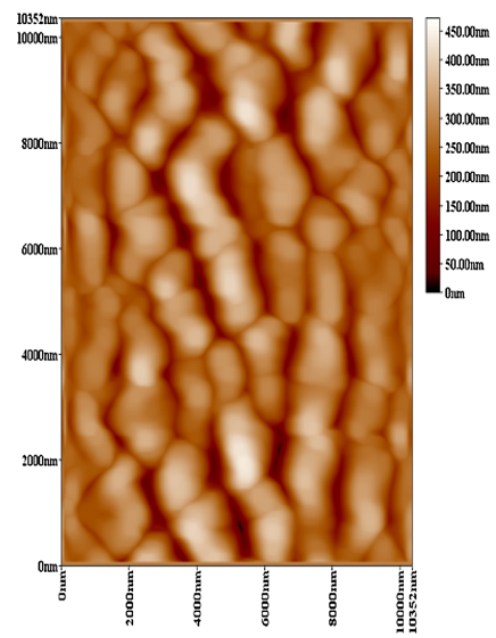

(b)

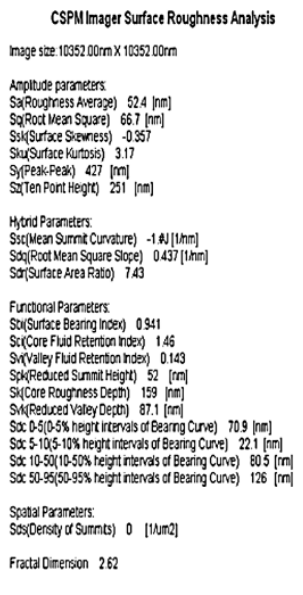

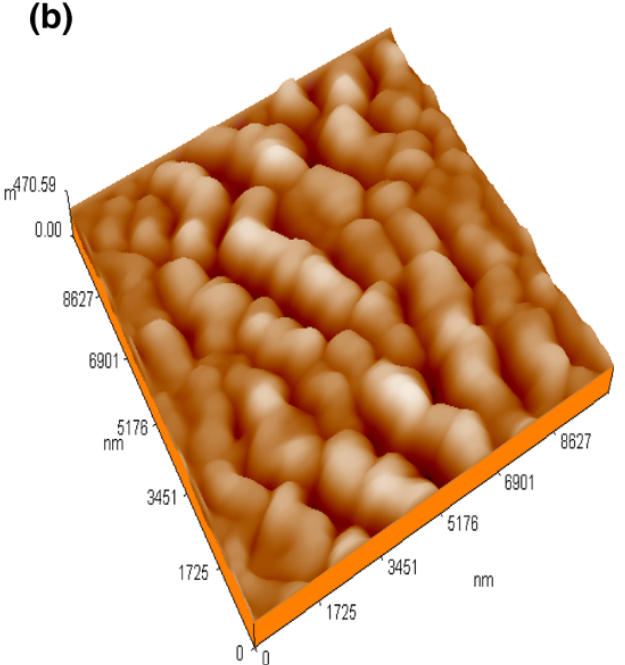

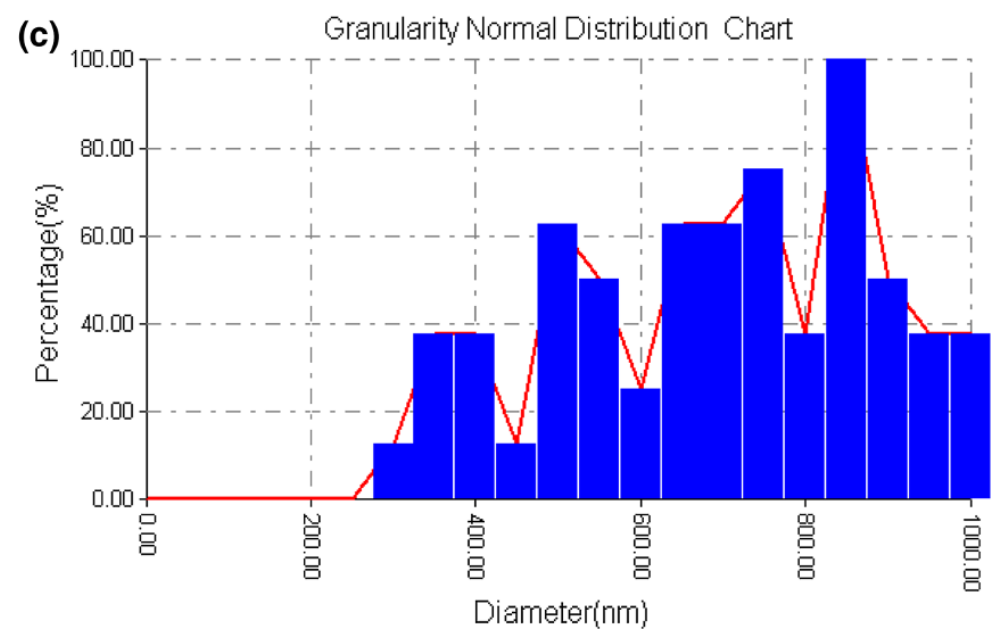

Fig. 4 AFM images of Ag deposited at room temperature. a The 2D, cross section, b 3D and $\mathbf{c}$ granularity normal distribution chart 
Most of the diodes reported were fabricated from uniformly doped $n$-type $\mathrm{Si}$. These conditions include the type of starting material with its resistivity, anodization electrolyte, anodization current density, anodization time, porosity and PSi layer thickness. To characterize PSi diodes, the parameters which describe the $J-V$ characteristics of Schottky and $p-n$ junction diodes had been used (Canham 1997).

$J-V$ characteristics of PS diode are described by the equation:

$J=J_{0} \exp [(q V / k T)-1]$

where $k$ is the Boltzmann constant, $T$ is the absolute temperature and $J_{\mathrm{o}}$ is the constant reverse bias current density. For current transport across the barrier governed by thermionic emission, $J_{0}$ is given by the expression:
$J_{0}=A^{*} T^{2} \exp \left[-\Phi_{\mathrm{b}} / k T\right]$

where $A^{*}$ is the Richardson constant and $\Phi_{\mathrm{b}}$ is the height of the diode barrier. Measured $\mathrm{J}-\mathrm{V}$ characteristics are rarely ideal due to the voltage dependence of $A^{*}$ and $\Phi_{\mathrm{b}}$. To compensate for this ideality factor, $n$ can be introduced such that:

$J=J_{0} \exp [(q V / n k T)-1]$

Due to the ideality, the measured reverse bias current density does not saturate. The ideality factor $(n)$ in Eq. (3) can deviate from unity for thermionic emission-diffusion because both effective Richardson's constant and diode barrier lowering are functions of the applied voltage bias. The ideality factor is given by:

$n=\frac{q}{K T} \frac{\partial V}{\partial(\ln J)}$ (a)

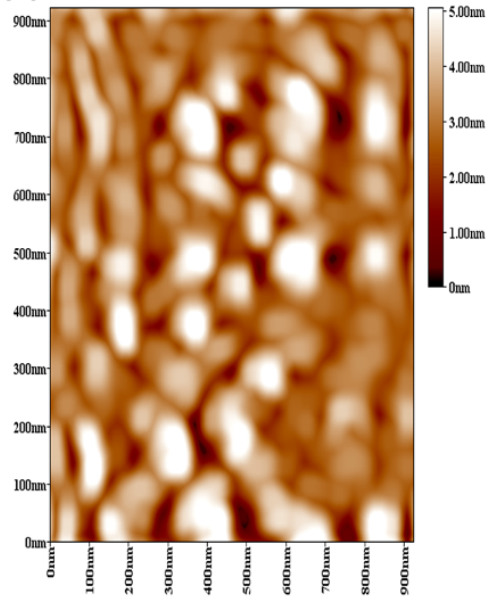

CSPM Imager Sufface Roughness Analysis Image size $923.46 \mathrm{~nm} \times$ X $921.58 \mathrm{~nm}$ Amolitude parameters: Sa(Roughness Average) $0.723[\mathrm{~nm}]$ SolRoot Mean Square) 0.914 [ntm] Shu(Surtace Kutrosis) 2.98 $4.99[\mathrm{~nm} \mid$ Hyorid Paramelers. SSc(Mean Sunnrit Curvature) -1. sdq(Root Mean Square Slope) 0.050 (1) / /nrt unctional Parameters Sol(Surtace Bearing Index) 2.06 ScicCore Flud Retertion Index) 1.61 SM(valey Fluid Retertion inoex) 0.174 SkC Core Roughress Depth) $20.877 \mathrm{lmm} /$ SW(ReducedValley Depth) 1.88 [nm Sod $0.5(0.5 \%$ height intervals of Bearing Curve) 0.444 [nm]

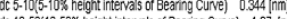
Sdc 10-50(10-50\% height intervals of Bearing Curve) 1.27 [nm Spatala Parameters

Sos(Density of Summits) 4.72 [11um2]

Fracta Dimension 2.35 (b)

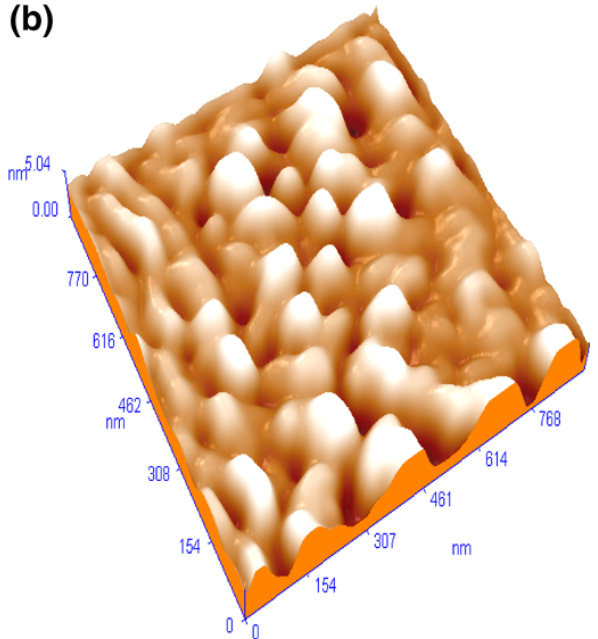

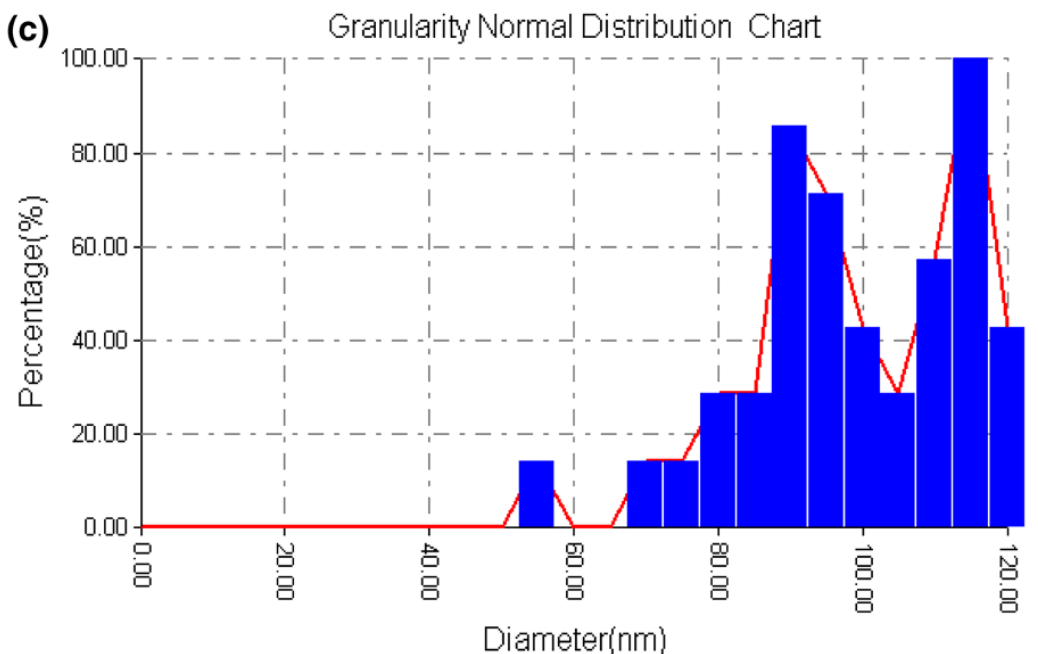

Fig. 5 AFM images of $\mathrm{Ag}_{2} \mathrm{O}$ prepared at oxidation temperature $350{ }^{\circ} \mathrm{C}$ and oxidation time $60 \mathrm{~s}$. a The $2 \mathrm{D}$, cross section, $\mathbf{b} 3 \mathrm{D}$ and $\mathbf{c}$ granularity normal distribution chart 
If the diode possesses series resistance, $R_{\mathrm{s}}$, then the applied voltage is distributed between the Schottky barrier and $R_{\mathrm{s}}$. Correcting for $R_{\mathrm{s}}$, the $J-V$ characteristics are expressed as:

$J=J_{0} \exp \left[\left(q\left(V-J A R_{\mathrm{s}}\right) M k T\right)-1\right]$

where $A$ is the area of the contact at the Schottky barrier. This expression is frequently called the diode equation as the $J-V$ characteristics of PSi of diode and can be described by the parameters $J_{\mathrm{s}}, R_{\mathrm{s}}$ and $n$. Several mechanisms have been proposed to explain the rectifying properties of PSi diodes. The three most common mechanisms are: (1) supply of minority carriers from the Si substrate or barrier at the PSi/Si junction, (2) Schottky barrier at the contact $_{1} /$ PSi junction and (3) $p-n$ junction within the PSi layer for PSi made from a c-Si (Muller et al. 1991; Shih et al. 1993). There is no one mechanism common to all PSi diodes, but rather the rectification mechanism depends upon the fabrication conditions of the PSi diode (1997). In the present paper, the properties of $p-\mathrm{Ag}_{2} \mathrm{O} / \mathrm{PSi} / \mathrm{c}-\mathrm{Si}$ heterojunctions device prepared by rapid thermal oxidation (RTO) of silver film have been measured and discussed.

\section{Experimental work}

The substrate used was (100) $n$ - and $p$-type, single-crystal silicon with a resistivity of $0.3-3 \Omega \mathrm{cm}$. These substrates are cut into $1.5 \times 1.5 \mathrm{~cm}^{2}$ pieces. Initially, the $\mathrm{Si}$ wafers were cleaned successively in a sonicating bath with $\mathrm{CCl}_{4}$, toluene, acetone, ethyl alcohol and $18.5 \mathrm{M} \Omega \mathrm{cm}$ deionized water. Electrochemical anodization was performed in dark to produce porous Si layers on polished $p$-type, (100) oriented Si wafers with a resistivity of $0.3-3 \Omega \mathrm{cm}$ and a thickness of $\sim 508 \mu \mathrm{m}$, using a 1:3 mixture of $48 \% \mathrm{HF}: 98 \%$ ethanol as an electrolyte. For $n$-type $\mathrm{Si}$ (100) wafers with a resistivity of $0.3-3 \Omega \mathrm{cm}$ and a thickness of $\sim 508 \mu \mathrm{m}$, the etching was (a)

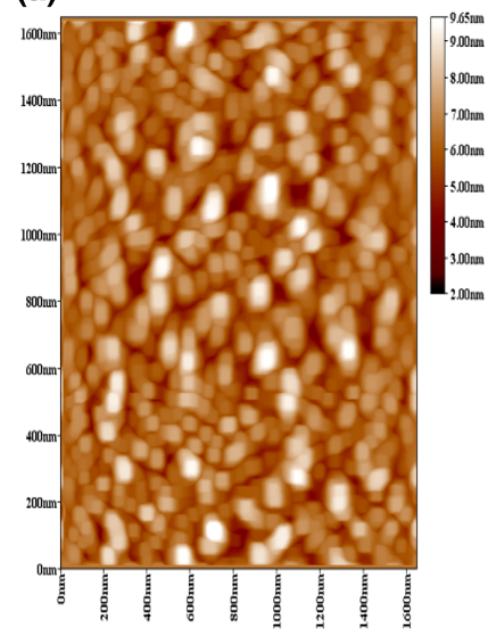

(b)

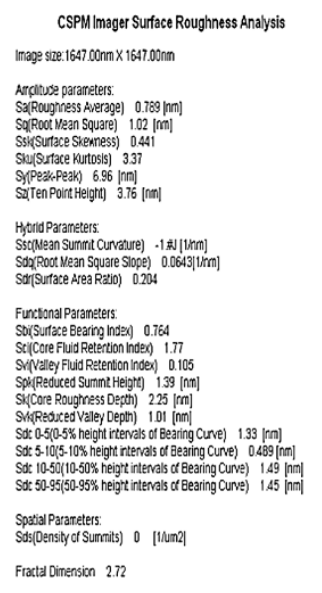

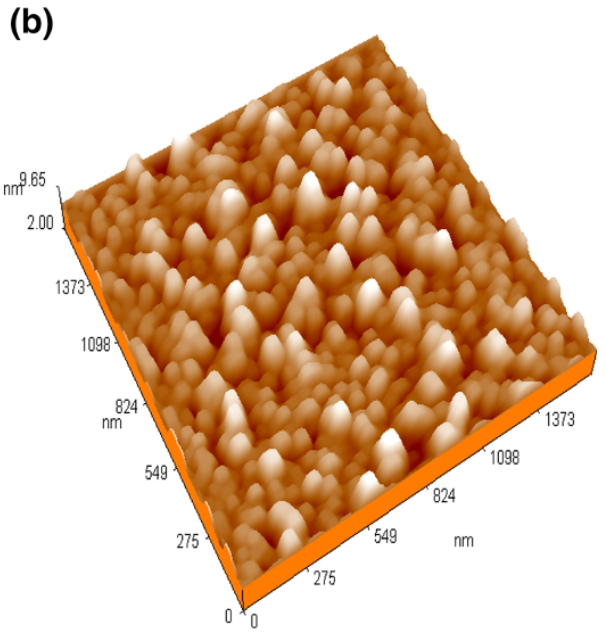

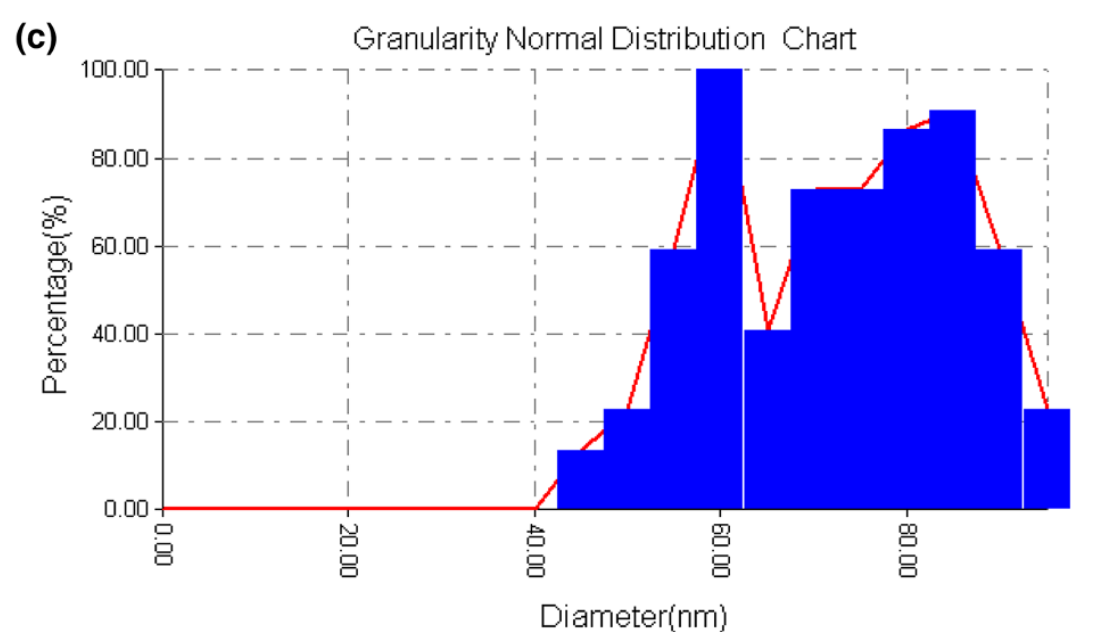

Fig. 6 AFM images of $\mathrm{Ag}_{2} \mathrm{O}$ prepared at oxidation temperature $350{ }^{\circ} \mathrm{C}$ and oxidation time $90 \mathrm{~s}$. a The $2 \mathrm{D}$, cross section, $\mathbf{b} 3 \mathrm{D}$ and $\mathbf{c}$ granularity normal distribution chart

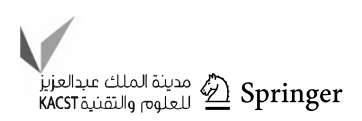


carried out in light using a halogen lamp $(100 \mathrm{~W})$. The anodization was carried out with the distance between the $\mathrm{Si}$ substrate to the Pt counter electrode fixed at $\sim 2.5 \mathrm{~cm}$, using a current density of $25 \mathrm{~mA} / \mathrm{cm}^{2}$ for a fixed time of $15 \mathrm{~min}$. PSi layers were fabricated by PECE process for $n$-type c-Si wafer and by ECE for $p$-type c-Si wafer. Teflon was used to fabricate the ECE cell that had a circular aperture at the bottom that is sealed with c-Si samples. The cell was a twoelectrode system connected to the c-Si samples as the anode and platinum $(\mathrm{Pt})$ as the cathode. The cell was called PECE if the illumination was positioned over the $n$-type $\mathrm{c}$-Si samples for maximum possible illumination and to generate the required holes for dissolution (Lehmann 1993). In contrast, the cell is called ECE if the $p$-type c-Si samples were not illuminated (Fig. 2a). The PECE cell had a circular aperture at the bottom sealed with the c-Si sample. The cell, made of Teflon, was a two-electrode system connected to the c-Si sample as the anode and platinum as the cathode (Fig. 2b). After the anodization, the PSi layers were dried in the following way to reduce the capillary stress using pentane, which has very low surface tension and no chemical reactivity with the PSi layer. The samples were rinsed first with pentane, then with $98 \%$ methanol and finally with deionized water $(18.5 \mathrm{M} \Omega \mathrm{cm})$. Next, the samples were dried at about $60{ }^{\circ} \mathrm{C}$ on a hot plate rather than drying in the $\mathrm{N}_{2}$ nozzle in order to avoid cracking and peeling of the PSi layer.

High purity (99.99\%) Ag thin film was deposited on the $n$-Si, $p$-Si, $n$-PSi and $p$-PSi substrates by thermal evaporation system type (Edwards) at $10^{-6}$ torr. Thickness (100 nm) of $\mathrm{Ag}_{2} \mathrm{O}$ thin film was grown on glass, $n$-Si, $p$-Si, $n$-PSi and $p$-PSi by rapid photothermal oxidation of deposited $\mathrm{Ag}$ film using a halogen lamp $350{ }^{\circ} \mathrm{C}$ for $90 \mathrm{~s}$ in static air. The experimental set-up and details are given elsewhere (Arenas et al. 2006). Figure 3 gives the calibration curve of the lamp, where two distinct regions are noticed. In the first region, the voltage increased with increasing temperature, while in the second region, the temperature was constant and it is in this region where RTO was accomplished.

The ohmic contacts of the photodiode were made by depositing a thick film of $\mathrm{Al}$ on the back surface of the (a)

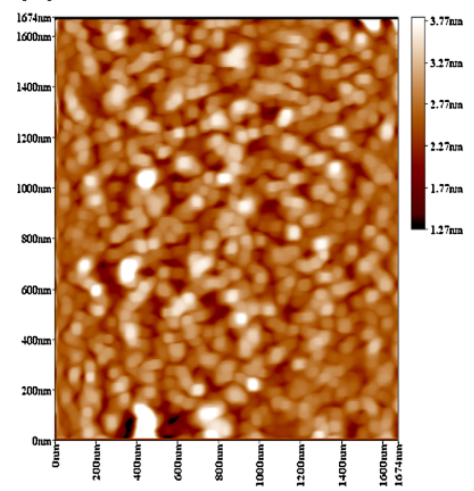

(b)

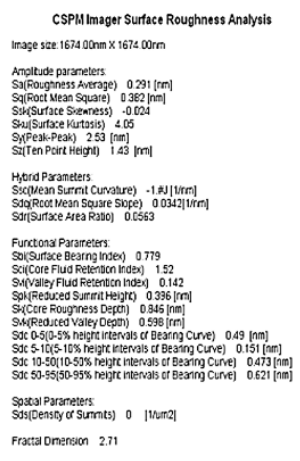

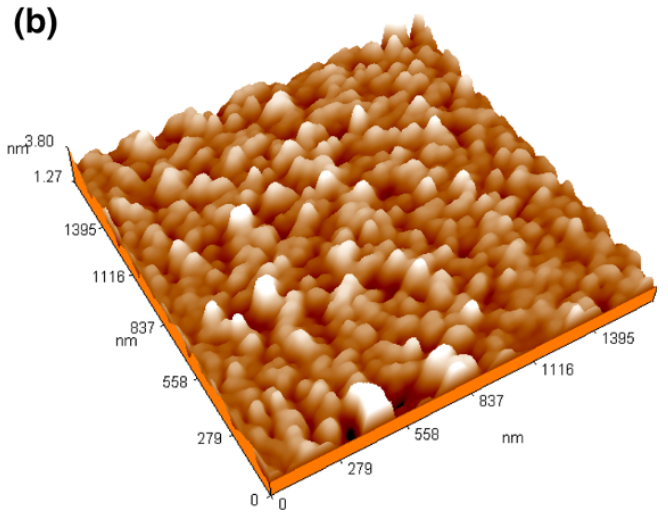

(c)

Granularity Normal Distribution Chart

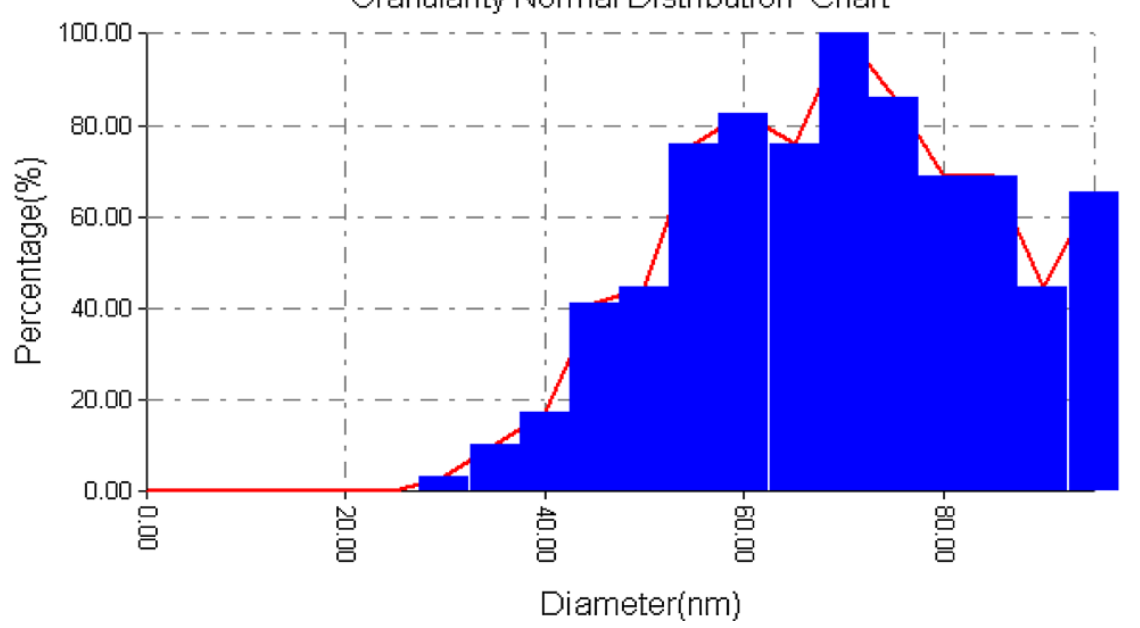

Fig. 7 AFM images of $\mathrm{Ag}_{2} \mathrm{O}$ prepared at oxidation temperature $350{ }^{\circ} \mathrm{C}$ and oxidation time $120 \mathrm{~s}$. a The $2 \mathrm{D}$, cross section, b $3 \mathrm{D}$ and c granularity normal distribution chart 
silicon and on thick film of the $\mathrm{Ag}_{2} \mathrm{O}$ film through special mask. The planar photosensitive area of the photodiode was around $2 \times 2 \mathrm{~cm}^{2}$. Porosity and thickness are the most important parameters that characterize the porous silicon layers (Canham et al. 1991). Porosity is defined as the fraction of void within the porous silicon layer. As a general rule, the samples in the low porosity range from 0 to $30 \%$, the medium porosity range from 30 to $70 \%$, and the high porosity range is from 70 to $100 \%$. An estimation of the porosity is obtained gravimetrically: first, the weight of the virgin wafer is measured before anodization $\left(M_{1}\right)$, then after anodization $\left(M_{2}\right)$, and finally after dissolution of the porous silicon layer $\left(M_{3}\right)$ in a $1 \mathrm{M}$ solution of sodium hydroxide $(\mathrm{NaOH})$. After determining these values, the porosity is given by the following equation (Vial and Derrien 1995):

Porosity $\%=\frac{M_{1}-M_{2}}{M_{1}-M_{3}}$
This relationship works best in the medium porosity range, for thick layers $(>5 \mu \mathrm{m})$ and for large anodization areas because the difference in mass is larger than the magnitude of the error. However, when the porous silicon layer is thin $(<200 \mathrm{~nm})$, the mass difference is the same order of magnitude as the error in measurements, and the porosity value obtained is unreliable. Porosity is greatly affected by the anodization current density, etching time and hydrofluoric acid concentration (Thesis 2000). The thickness of the layers is another important parameter that is closely related to the etching parameters of anodization time and hydrofluoric acid concentration. Similar to porosity, the thickness can be approximated gravimetrically by the following equation:

$T_{\mathrm{PSi}}=K * J^{m} * t$

where $T_{\mathrm{PSi}}$ in $(\mathrm{cm}), J=$ etching current density $\left(\mathrm{mA} / \mathrm{cm}^{2}\right)$ and $t=$ etching time (s). Constants $K$ and $m$ are tabulated in Table 1 and depend on HF concentration. Another way (a)

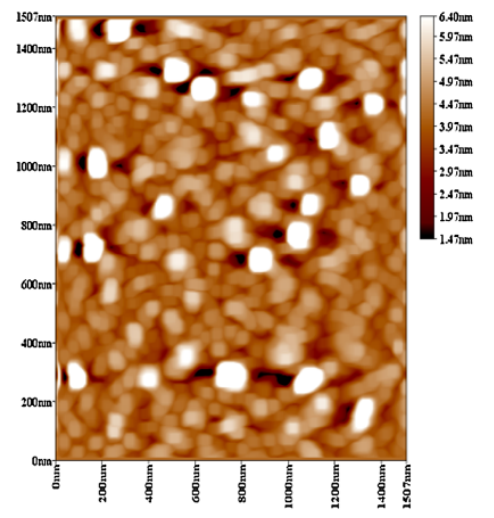

(b)

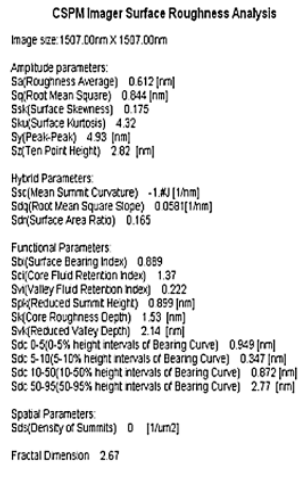

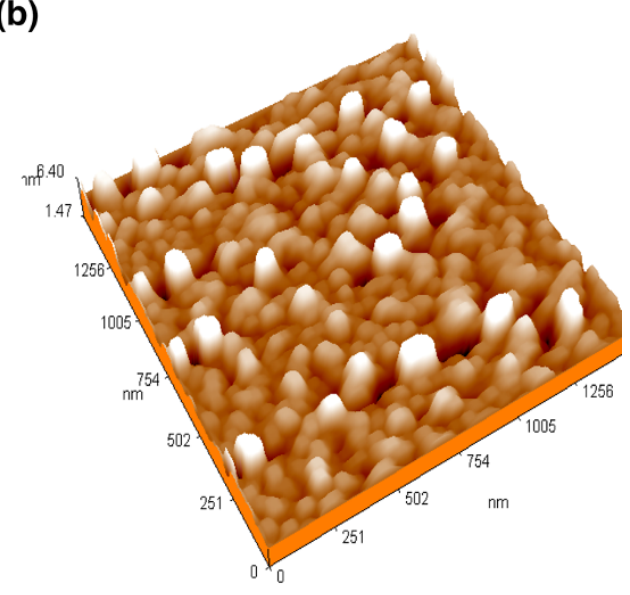

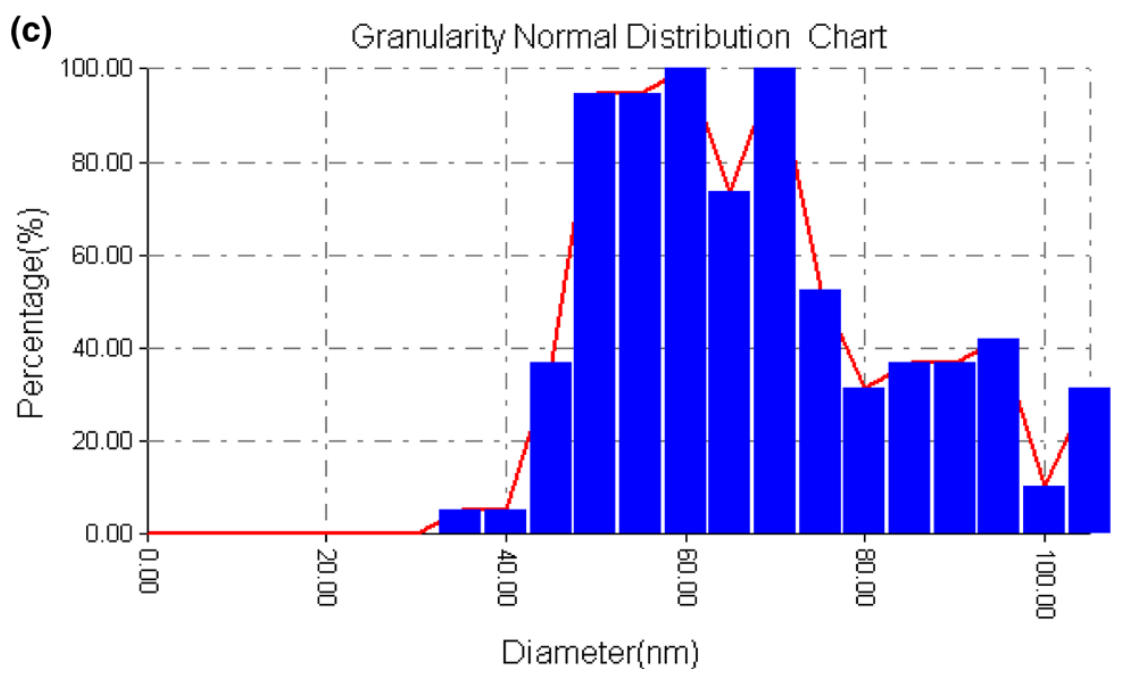

Fig. 8 AFM images of $\mathrm{Ag}_{2} \mathrm{O}$ prepared at oxidation temperature $350{ }^{\circ} \mathrm{C}$ and oxidation time $150 \mathrm{~s}$. a The $2 \mathrm{D}$, cross section, b $3 \mathrm{D}$ and c granularity normal distribution chart 
to measure the film thickness is by direct determination using the scanning electron microscopy (SEM) or atomic force microscopy (AFM) (Canham 1997).

Porous silicon has a very large surface area, defined as the accessible area of solid surface per unit of material. This characteristic gives porous silicon the ability to act as a host to many inorganic and organic materials, resulting in many new potential applications. The surface area of porous silicon typically ranges from 1 to $500 \mathrm{~m}^{2} / \mathrm{cm}^{3}$, depending on the pore size distribution, which is greatly affected by the many anodization parameters, and on the method used to measure it (Canha 1993; Ben-Chorin et al. 1995). $I-V$ under dark and white light illumination conditions of $p-\mathrm{Ag}_{2} \mathrm{O} / n-\mathrm{Si}, p-\mathrm{Ag}_{2} \mathrm{O} / p-\mathrm{Si}, p-\mathrm{Ag}_{2} \mathrm{O} / n-\mathrm{PSi} / n-\mathrm{Si}$ and $p-\mathrm{Ag}_{2} \mathrm{O} / p-\mathrm{PSi} / n-\mathrm{Si}$ heterojunction were examined using $\mathrm{A}$ Kiethley-616 electrometer was used to measure the current flow in a solar cell, manufactured from a structure produced in dark condition with voltage $0-4.5 \mathrm{~V}$ in forward biasing and $0-6 \mathrm{~V}$ in reverse biasing. The manufactured solar cells were illuminated by varying light power from halogen lamp and the current was measured in reverse bias with a voltage range of $0.2-4 \mathrm{~V}$.

\section{Results and discussion}

Atomic force microscopy of $\mathrm{Ag}_{2} \mathrm{O}$ film

It is known that the surface properties of the transparentconducting oxide films influence their optical and electrical properties which are important factors for applications in optoelectronic devices; in principle, the increase in surface roughness of the films leads to a decrease in the efficiency for photovoltaic properties, and therefore, it is very important to investigate the surface morphology of the films. (Van and Dinh 1998). The AFM technique uses a (a)

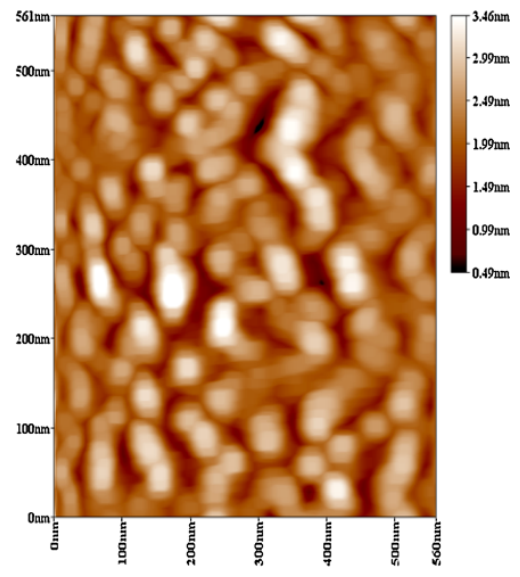

(b)
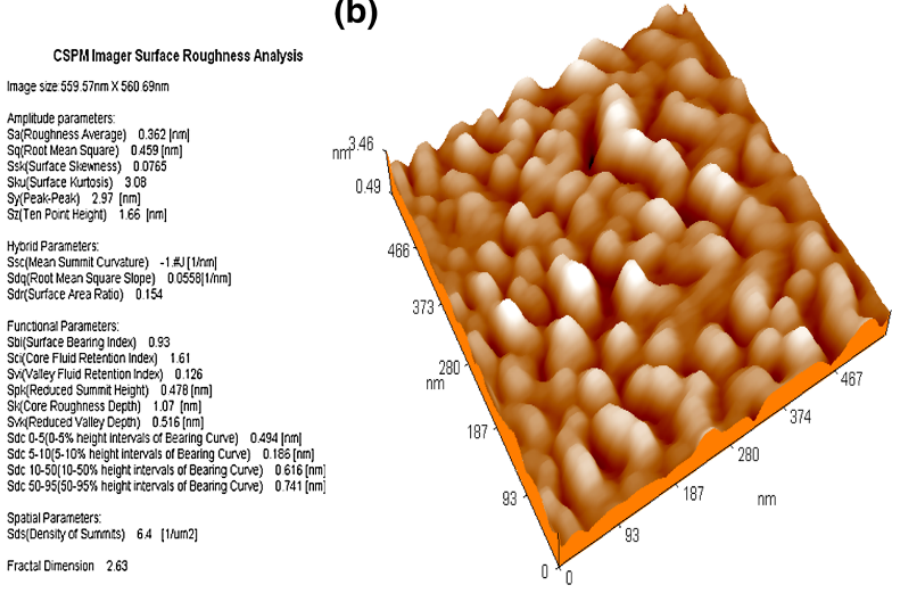

(c) Granularity Normal Distribution Chart

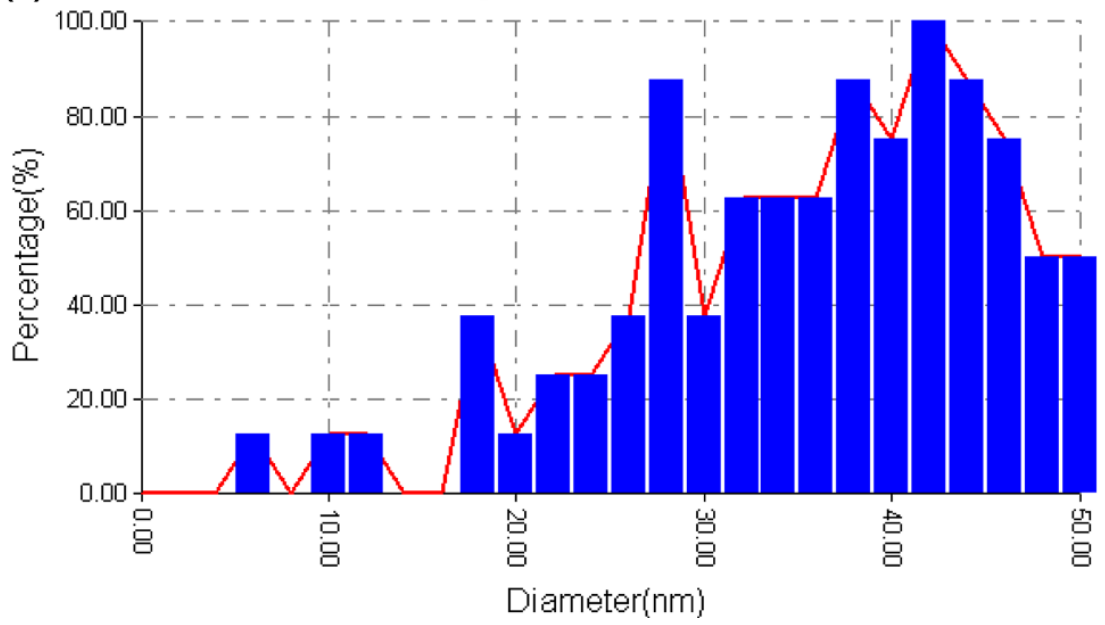

Fig. 9 AFM images of $\mathrm{Ag}_{2} \mathrm{O}$ prepared at oxidation temperature $350{ }^{\circ} \mathrm{C}$ and oxidation time $90 \mathrm{~s}$ with thickness $50 \mathrm{~nm}$. a The $2 \mathrm{D}$, cross section, b $3 \mathrm{D}$ and $\mathbf{c}$ granularity normal distribution chart 
laterally moving tip, while the cantilever reflects the sample's topography, or the $Z$ measurements. Even though the tip is very sharp, it is impossible to gather the information from the underside of specimen. The spherical particle will be viewed as a bump by the AFM. To correct the AFM image for this effect, some deconvolution techniques are used. The surface morphology of $\mathrm{Ag}_{2} \mathrm{O}$ films as observed from the (AFM-AA3000, Angstrom Advanced Inc., USA) micrographs proves that the grains are uniformly distributed within the scanning area $(1,000 \times 1,000 \mathrm{~nm})$ with individual columnar grains extending upwards as shown in Fig. 4, 5, 6, 7, 8, 9, 10, 11 and 12 . The grain size decreases with the increase in oxidation time, while the films presented uniformity. Since the size grain decreases in dimension when the film thickness decreases, it suggests that the charge transport is occurring predominantly intragrain in cases of lower thickness, or equivalent to greater grains, and that there is a preferential charge transport inter-grain in greater thickness samples, where there are more interface grains; in this kind of microstructure, it is usually not dominated by bulk properties but by grain walls, which either act as low conductivity blockades or as high conductivity carrier accumulation regions. This surface characteristic is important for applications such as solar cells, gas sensors and catalysts (Gyogy and Axente 2000; Al-Hardan and Abdulllah 2009. The root mean square (RMS) roughness of the film surface roughness was prepared at different conditions as listed in Table 2.

\section{X-ray diffraction}

The structure and lattice parameters of $\mathrm{Ag}$ and $\mathrm{Ag}_{2} \mathrm{O}$ films are analyzed by a LabX XRD 6000 SHIMADZU XRdiffractometer with $\mathrm{Cu} \mathrm{K} \alpha$ radiation (wavelength 1.54059 $\AA$, voltage $30 \mathrm{kV}$, current $15 \mathrm{~mA}$, scanning speed $=$ $4 \% \mathrm{~min}$ ) as illustrated in Fig. 13a, b. The crystallinity of the produced material was characterized using $\mathrm{X}$-ray diffraction (XRD). This technique was also employed by other group which gives an indication about the grain size and formation material type of the prepared thin film. The following figures show the XRD patterns for samples grown at $350{ }^{\circ} \mathrm{C}$ oxidation temperature and $90 \mathrm{~s}$ oxidation time. For Ag films (a)

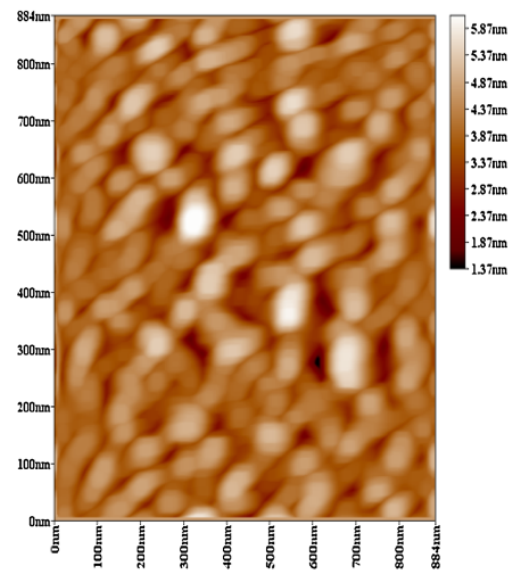

(b)
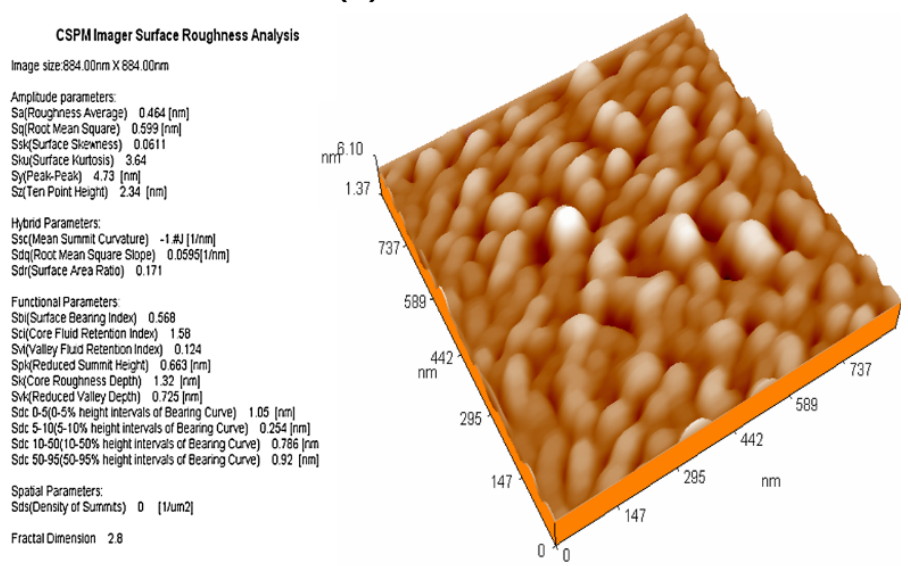

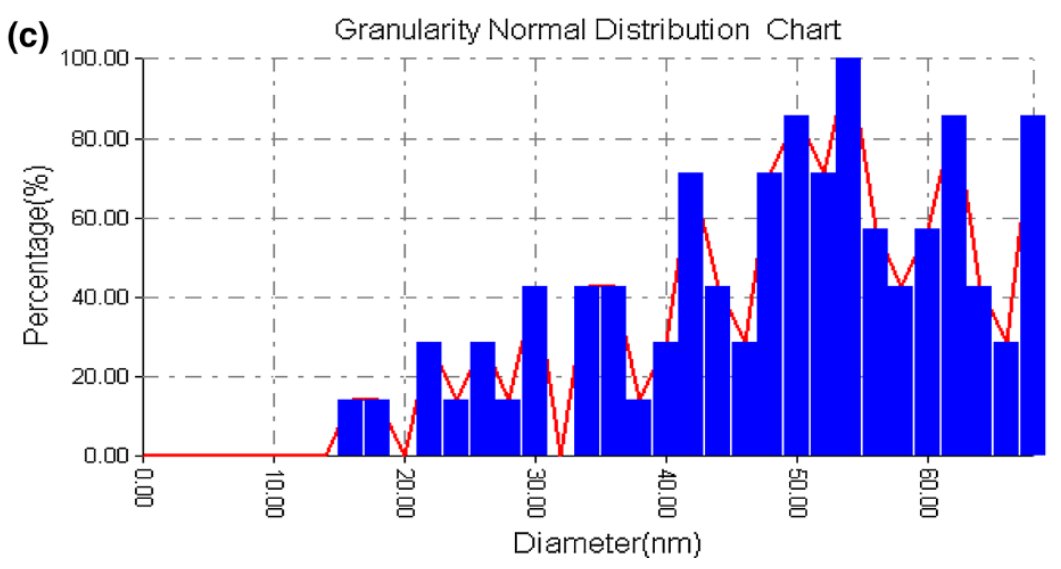

Fig. 10 AFM images of $\mathrm{Ag}_{2} \mathrm{O}$ prepared at oxidation temperature $350{ }^{\circ} \mathrm{C}$ and oxidation time $90 \mathrm{~s}$ with thickness $75 \mathrm{~nm}$. a The $2 \mathrm{D}$, cross section, b $3 \mathrm{D}$ and $\mathbf{c}$ granularity normal distribution chart 
depositing on glass substrate, four peaks could be recognized in Fig. 13a. The film is polycrystalline according to the ASTM standards where (111), (200), (110) and (311) Ag, with lattice constant $a=4.077 \AA$, respectively, could be recognized. This is related to the formation of silver thin film and such result indicates that no formation of the oxide film occurs on glass substrate. $\mathrm{Ag}_{2} \mathrm{O}$ film thickness of $100 \mathrm{~nm}$ prepared at $90 \mathrm{~s}$ oxidation time and $350{ }^{\circ} \mathrm{C}$ oxidation temperature (Fig. 13b) shows that the structures of films are clearly improved where there is a significant increase in peak intensity at (111) and (101) planes. This indicates the formation of nearly stoichiometry $\mathrm{Ag}_{2} \mathrm{O}$ films with cubic structure.

Scan of electron microscope (SEM) for porous silicon

The SEM study was carried out by VEGA TESCAN-SEM in University of Technology, Baghdad, Iraq at $20-30 \mathrm{kV}$. The reproducibility of structural, electrical and optical properties of porous silicon is a fundamental issue (Pascual et al. 2002) that helps in device fabrication related to PSi.
In this work, we stick to the optimum experimental parameters in respect of the PSi preparation with desired reproducibility. The porosity (gravimetric) values of the PSi layers formed on $n$-type and $p$-type $\mathrm{Si}$ wafers (henceforth, called as $n$-PSi and $p$-PSi, respectively) were 60 and $75 \%$, respectively, for an etching time of $15 \mathrm{~min}$ using Eq. (6). The etching time has been fixed at $15 \mathrm{~min}$ with the current density of $25 \mathrm{~mA} / \mathrm{cm}^{2}$ as an optimum condition since the reproducibility of porosity values lies within 2-3\%. It is well known that PSi can exist in different microstructural forms depending upon various electrochemical parameters, silicon doping and resistivity (Bisi et al. 2002). According to IUPAC classification of pore size, our PSi samples should belong to either the mesoporous $(2-50 \mathrm{~nm})$ or the nanoporous $(<2 \mathrm{~nm})$ region as evident from the plan-view SEM micrograph (Fig. 14a, b). As expected, the PSi surface on both $n$ - and $p$-type Si wafers is characterized by the presence of large number of pores, more or less, regular in size.

It is established (Kocka et al. 1995) that higher thickness of porous silicon poses the danger of a bad electrical (a)

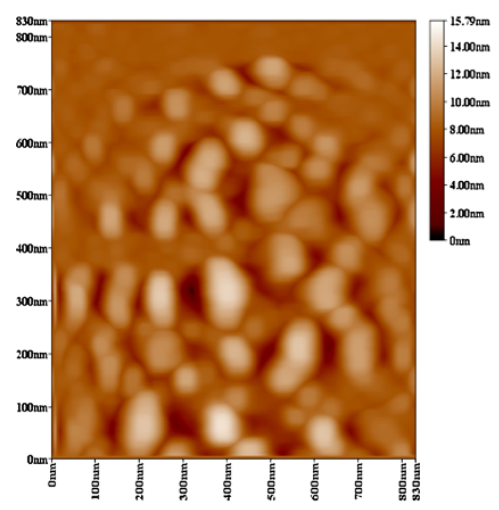

(b)

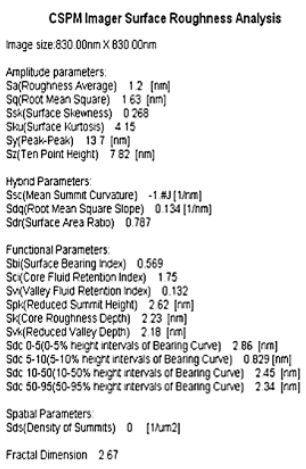

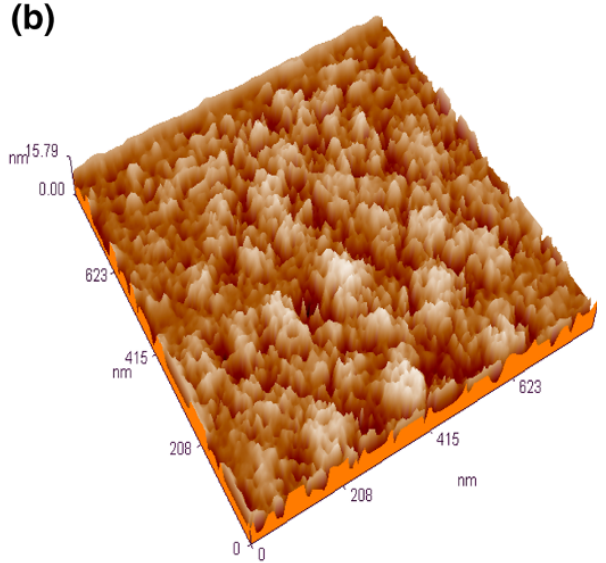

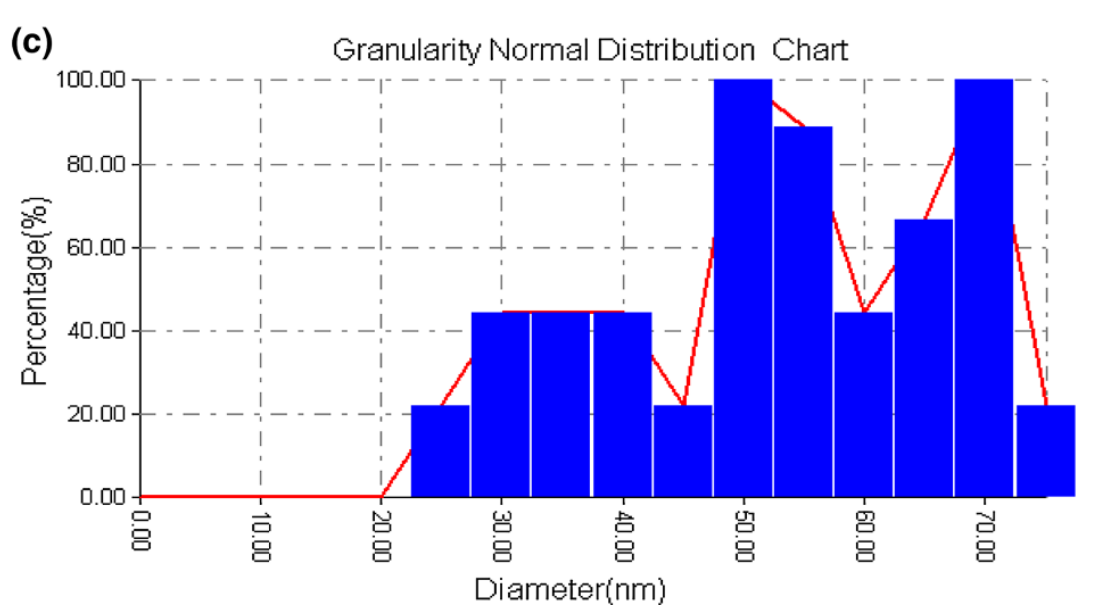

Fig. 11 AFM images of $\mathrm{Ag}_{2} \mathrm{O}$ prepared at oxidation temperature $350{ }^{\circ} \mathrm{C}$ and oxidation time $90 \mathrm{~s}$ with thickness $100 \mathrm{~nm}$. a The $2 \mathrm{D}$, cross section, $\mathbf{b} 3 \mathrm{D}$ and $\mathbf{c}$ granularity normal distribution chart 
(a)

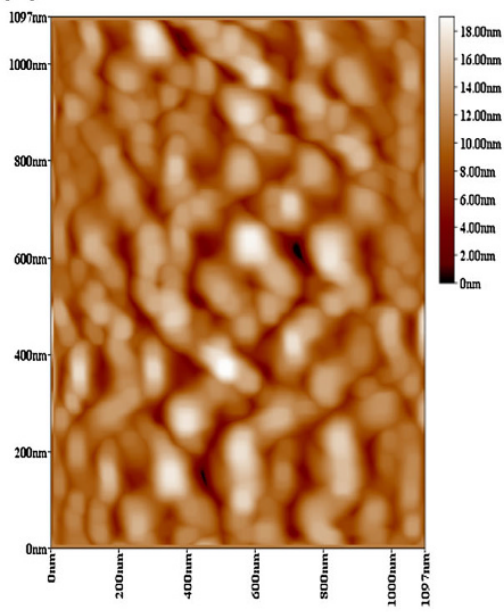

(b)

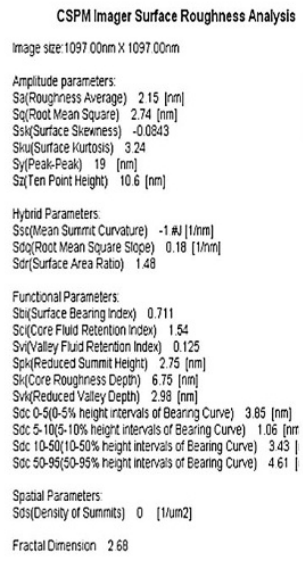

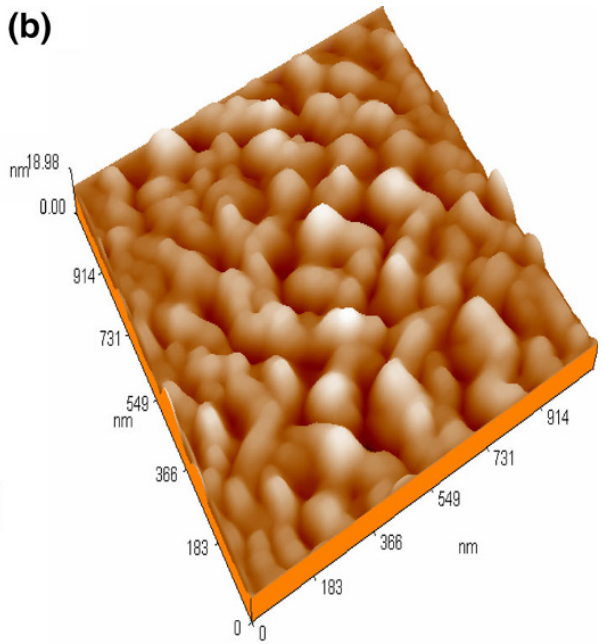

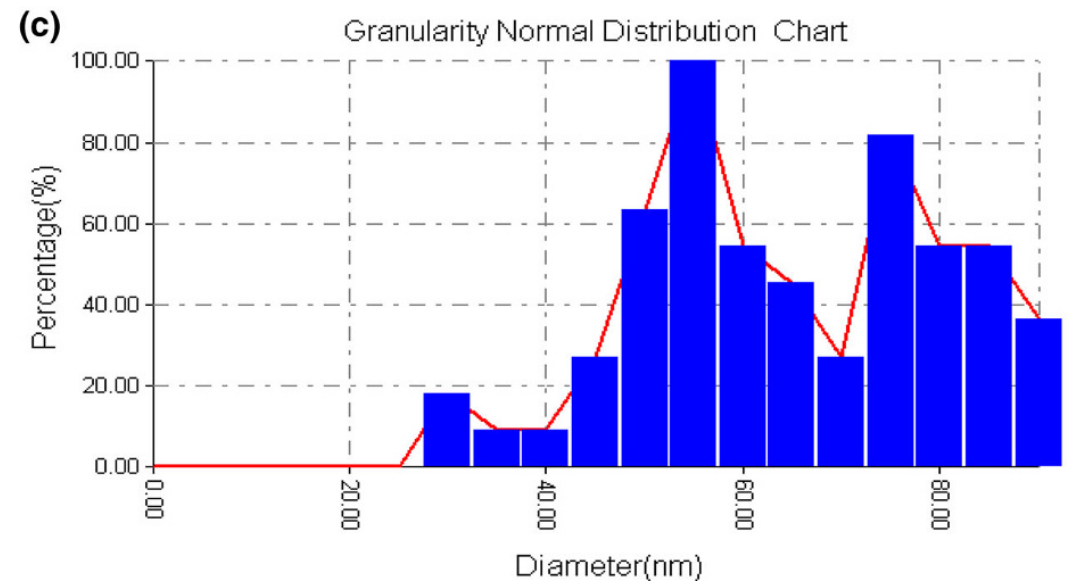

Fig. 12 AFM images of $\mathrm{Ag}_{2} \mathrm{O}$ prepared at oxidation temperature $350{ }^{\circ} \mathrm{C}$ and oxidation time $90 \mathrm{~s}$ with thickness $125 \mathrm{~nm}$. a The $2 \mathrm{D}$, cross section, $\mathbf{b} 3 \mathrm{D}$ and $\mathbf{c}$ granularity normal distribution chart

Table 2 The grain size of $\mathrm{Ag}_{2} \mathrm{O}$ film prepared at different oxidation time and film thickness

\begin{tabular}{lcllc}
\hline Sample & $\begin{array}{l}\text { Grain size } \\
(\mathrm{nm})\end{array}$ & $\begin{array}{l}\text { Sa (roughness } \\
\text { average) }(\mathrm{nm})\end{array}$ & $\begin{array}{l}\text { Sq (root mean } \\
\text { square) }(\mathrm{nm})\end{array}$ & $\begin{array}{l}\text { Sz (ten point } \\
\text { height) }(\mathrm{nm})\end{array}$ \\
\hline $\mathrm{Ag}$ & 671.32 & 52.4 & 66.7 & 251 \\
$150 \mathrm{~nm}, 350{ }^{\circ} \mathrm{C}$ and $60 \mathrm{~s}$ & 76.08 & 0.723 & 0.914 & 3.37 \\
$150 \mathrm{~nm}, 350{ }^{\circ} \mathrm{C}$ and $90 \mathrm{~s}$ & 49.84 & 0.789 & 1.02 & 3.76 \\
$150 \mathrm{~nm}, 350{ }^{\circ} \mathrm{C}$ and $120 \mathrm{~s}$ & 46.83 & 0.291 & 0.382 & 1.43 \\
$150 \mathrm{~nm}, 350^{\circ} \mathrm{C}$ and $150 \mathrm{~s}$ & 45.40 & 0.612 & 0.844 & 2.82 \\
$50 \mathrm{~nm}, 350{ }^{\circ} \mathrm{C}$ and $90 \mathrm{~s}$ & 14.64 & 0.362 & 0.459 & 1.66 \\
$75 \mathrm{~nm}, 350{ }^{\circ} \mathrm{C}$ and $90 \mathrm{~s}$ & 27.76 & 0.464 & 0.599 & 2.34 \\
$100 \mathrm{~nm}, 350{ }^{\circ} \mathrm{C}$ and $90 \mathrm{~s}$ & 30.41 & 1.2 & 1.63 & 7.82 \\
$125 \mathrm{~nm}, 350{ }^{\circ} \mathrm{C}$ and $90 \mathrm{~s}$ & 42.40 & 2.15 & 2.74 & 10.6 \\
\hline
\end{tabular}

Figure $14 \mathrm{a}, \mathrm{b}$ shows the topography of the porous silicon formed by the electrochemical anodization process of monocrystalline silicon in HF-based solution at $25 \mathrm{~mA} / \mathrm{cm}^{2}$ for $15 \mathrm{~min}$ in dark and white at room temperature. As shown, a nearly uniform distribution of pores and a sponge-like structure of the porous layer are contact on the PSi device, resulting in the worst efficiency characteristics, although it helps in improving the power efficiency. The thickness values of the PSi layers formed on $n$ - and $p$-type Si wafers (henceforth, called as $n$-PSi and $p$-PSi, respectively) were 25.50 and $48.66 \mu \mathrm{m}$, respectively, for an etching time of 15 min using Eq. (7). 


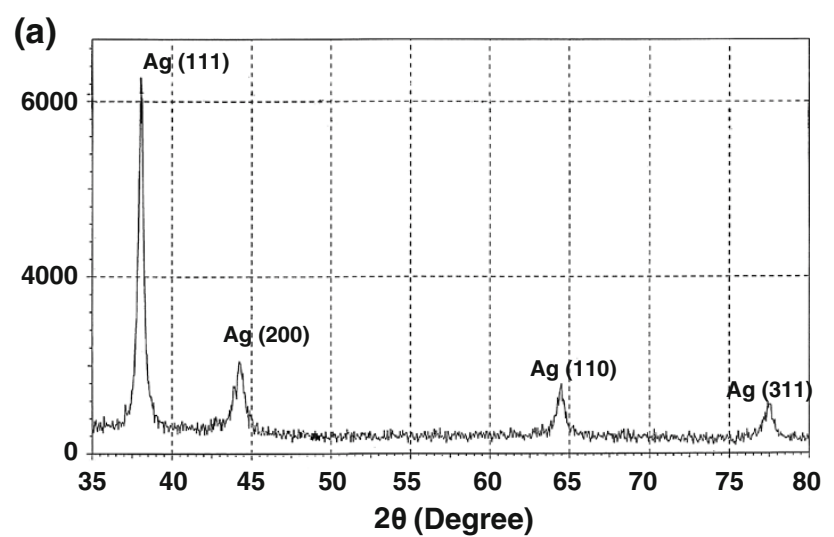

(b)

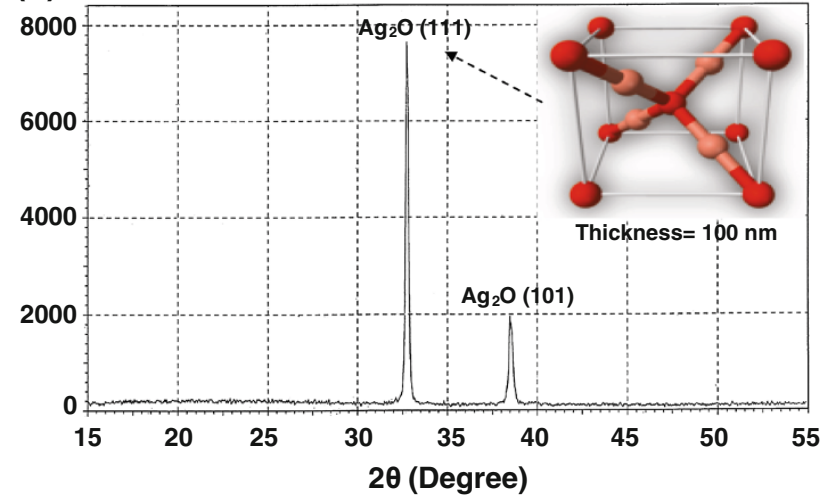

Fig. 13 XRD pattern of Ag thin film prepared at a room temperature and $\mathbf{b} T=350{ }^{\circ} \mathrm{C}$ oxidation temperature and $90 \mathrm{~s}$ oxidation time

obtained. The porosity and thickness of porous silicon is a major concern of researchers in the field. However, understanding how to control PSi morphology is extremely difficult owing to the large number of controlling factors (Gaburro et al. 2000; Berger et al. 2001). The morphology of PSi is also strongly affected by the etching current density. The silicon dissolution process requires the presence of fluorine ions $(\mathrm{F}-)$ and holes $(\mathrm{h}+)$. As shown in Fig. 14c, when the fluorine ions are delivered faster than the holes, the inter-pore regions of PSi are depleted of holes and further etching occurs only at the pore tips, where the holes are focused by the electric field. When the current density decreases, the number of holes at the pore tips drops, which leads to smaller pore sizes. Thus, the porosity (defined as the percentage of void space in the material) can be precisely controlled by the etching current density.

Electrical measurements of constructed device

\section{$J-V$ characteristics in dark}

$J-V$ characteristics at forward and reverse bias in dark for $p-\mathrm{Ag}_{2} \mathrm{O} / p-\mathrm{Si}, p-\mathrm{Ag}_{2} \mathrm{O} / n-\mathrm{Si}, \quad \mathrm{Al} / p-\mathrm{PSi} / \mathrm{Al}, \mathrm{Al} / n-\mathrm{PSi} / \mathrm{Al}, p-$ $\mathrm{Ag}_{2} \mathrm{O} / p-\mathrm{PSi} / \mathrm{c}-\mathrm{Si}$ and $p-\mathrm{Ag}_{2} \mathrm{O} / n-\mathrm{PSi} / \mathrm{c}-\mathrm{Si}$ devices prepared at optimum condition $\left[\mathrm{Ag}_{2} \mathrm{O}\right.$ deposited of high purity $(\mathrm{Ag})$ thin film $(100 \mathrm{~nm})]$ are shown in Fig. 15. These characteristics are very important to describe the device performance and all device parameters depending on it. The results in Fig. 15 give the $J-V$ characteristics behavior of the four devices in the forward bias. Two regions are recognized: the first one represents recombination current, the first current established when the concentration of the generated carrier is larger than the intrinsic carrier concentration $\left(n_{\mathrm{i}}\right)$, i.e. $\left(n^{*} p>n_{\mathrm{i}}^{2}\right)$. The second region at high voltage represented the diffusion or bending region which depends on serried resistance.

The $J-V$ characteristics were given for $p-\mathrm{Ag}_{2} \mathrm{O} / p-\mathrm{Si}$, $p-\mathrm{Ag}_{2} \mathrm{O} / n-\mathrm{Si}, p-\mathrm{Ag}_{2} \mathrm{O} / p-\mathrm{PSi} / \mathrm{c}-\mathrm{Si}$ and $p-\mathrm{Ag}_{2} \mathrm{O} / n-\mathrm{PSi} / \mathrm{c}-\mathrm{Si}$ devices at optimum condition under reverse bias. It is clear that the curve contains two regions: the first is the generation of power where the reverse current is slightly increased with the applied voltage and this tends to generation of electron-hole pairs at low bias. In the second region, a significant increase in the reverse bias can be recognized. In this case, the current resulted from the diffusion of minority carriers through the junction. From the obtained result, it is clear that the current produce by $p-\mathrm{Ag}_{2} \mathrm{O} / n-\mathrm{Si}$ and $p-\mathrm{Ag}_{2} \mathrm{O} / n-\mathrm{PSi} / \mathrm{c}-\mathrm{Si}$ are less than that obtained from the $p-\mathrm{Ag}_{2} \mathrm{O} / p-\mathrm{Si}$ and $p-\mathrm{Ag}_{2} \mathrm{O} / p-\mathrm{PSi} / c-\mathrm{Si}$ which is related to the large junction resistant which reduces the leakage current. The enhancement in the reverse current is related to enhancement in the junction structure, which results in reducing the number of defects at semiconductor-semiconductor interfaces of the four junctions. These defects result from the strain due to crystal structure, lattice parameter and probably thermal expansion mismatch. In the forward bias, the forward voltage results in reducing the height of the potential barrier, therefore, majority carriers are able to cross the potential barrier, so that the diffusion current becomes greater than the drift current.

From the comparison between the results obtained for four devices prepared at optimum condition, it is recognized that the values of the current improved for $p-\mathrm{Ag}_{2} \mathrm{O} /$ $p$-Si and $p-\mathrm{Ag}_{2} \mathrm{O} / p$ - $\mathrm{PSi} / \mathrm{c}-\mathrm{Si}$ due to decrease in the resistivity for $p$-type silicon and porous silicon result in an increase in the electron concentration. This causes a decrease in the hole concentration and thus a reduction in $J_{\mathrm{S}}$ (Song et al. 2001). The ideality factor of four devices was estimated at the optimum conditions using Eq. (4) and it has been found to be 2-2.9, respectively, as shown in Table 3. These values refer to good rectification properties for four prepared devices. The large value of $n$ suggests that in this voltage region, the recombination in these devices occurs primarily in the junction depletion region and at the junction interface (Song et al. 2001). 
Fig. 14 SEM micrograph of PSi prepared at current density $J=25 \mathrm{~mA} / \mathrm{cm}^{2}$ and

$t=15 \mathrm{~min}$. a $n$-type porous silicon, $\mathbf{b} p$-type porous silicon and $\mathbf{c}$ schematic of PSi

formation. Etching occurs only at the pore tips where the holes $(\mathrm{h}+)$ are focused by the electric field
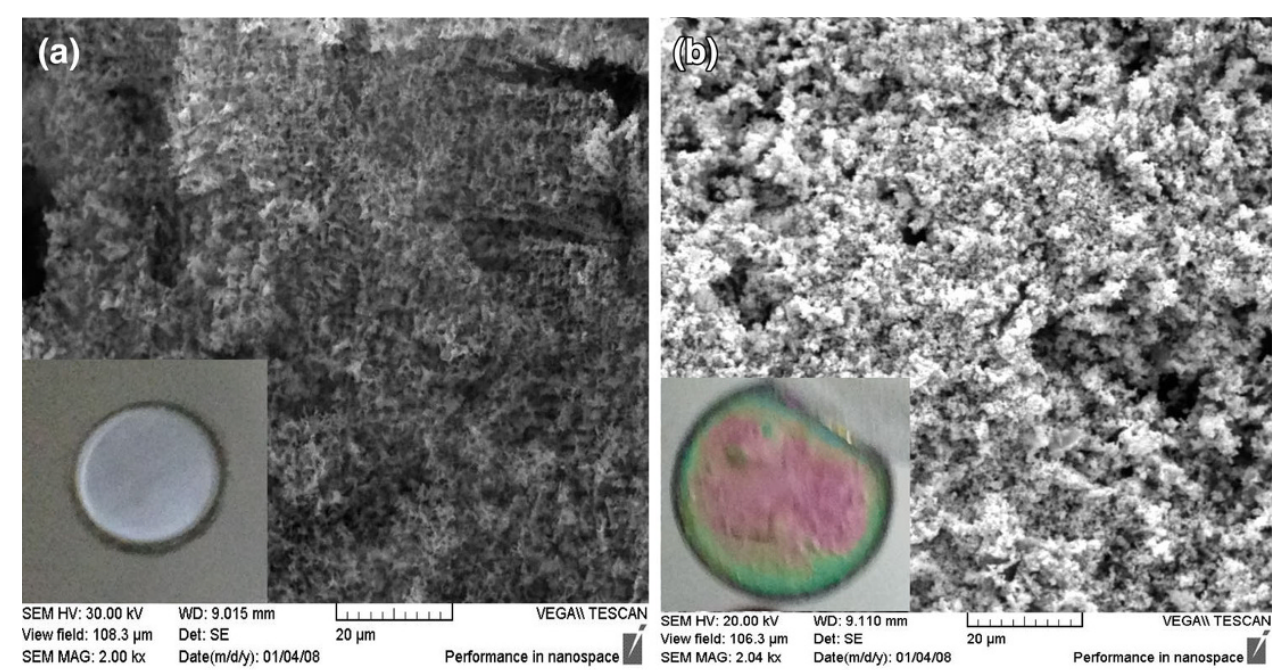

(c)

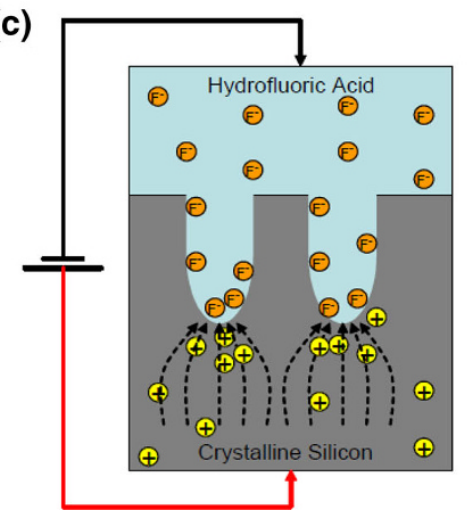

Fig. $15 J-V$ characteristic under forward and reverse bias of the all devices

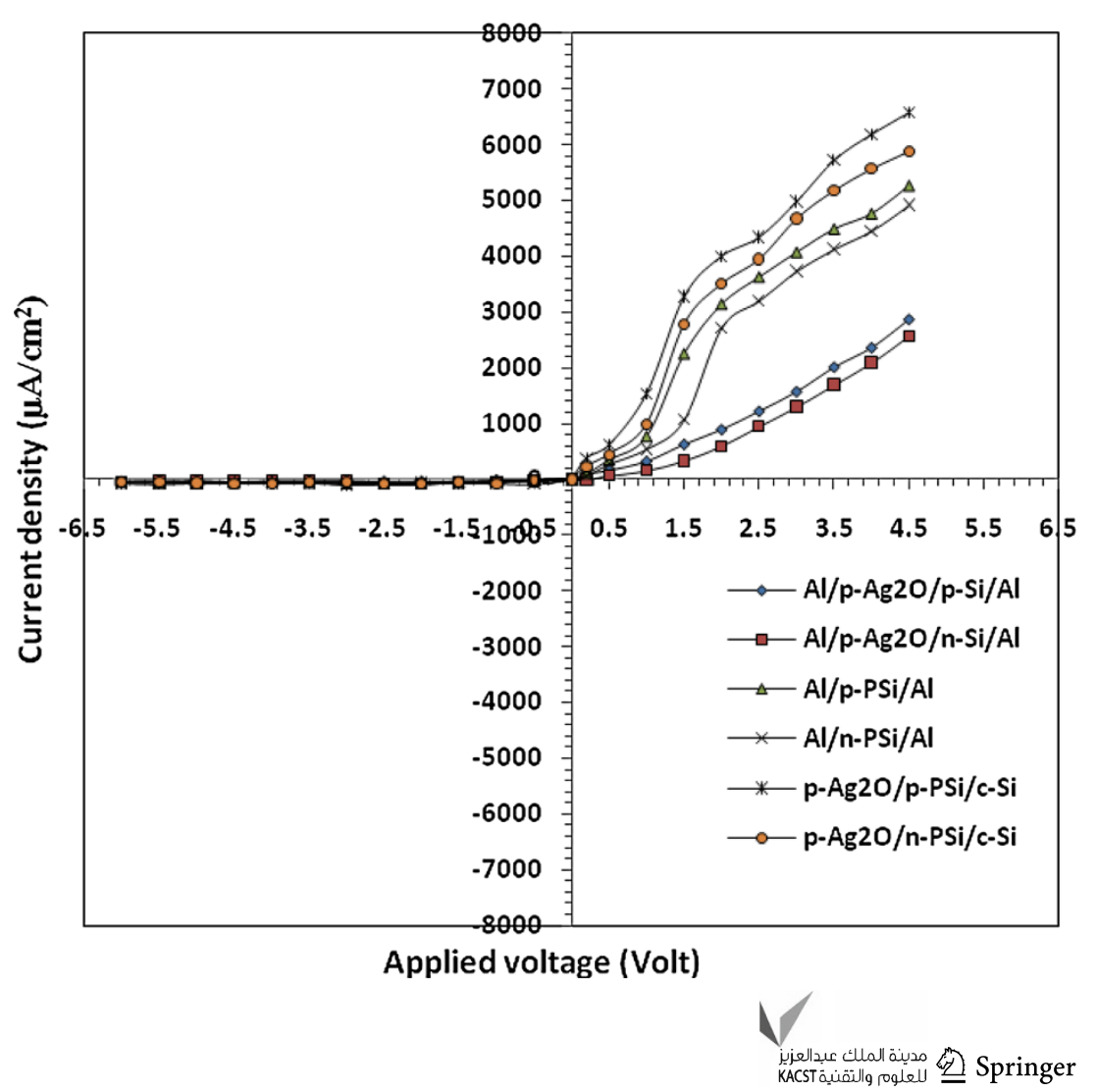


Table 3 Ideality factor $(n)$ of $\mathrm{Ag}_{2} \mathrm{O}$ devices prepared on $\mathrm{Si}$ and PSi substrate

\begin{tabular}{lll}
\hline Device & Ideality factor $(n)$ & $\begin{array}{l}\text { Potential barrier } \\
\text { height }\left(\Phi_{\mathrm{b}}\right)\end{array}$ \\
\hline$p-\mathrm{Ag}_{2} \mathrm{O} / p-\mathrm{Si}$ & 2.7 & 0.75 \\
$p-\mathrm{Ag}_{2} \mathrm{O} / n-\mathrm{Si}$ & 2.9 & 0.81 \\
$\mathrm{Al} / p-\mathrm{PSi} / \mathrm{Al}$ & 2.3 & 0.53 \\
$\mathrm{Al} / n-\mathrm{PSi} / \mathrm{Al}$ & 2.5 & 0.64 \\
$p-\mathrm{Ag}_{2} \mathrm{O} / p-\mathrm{PSi} / \mathrm{c}-\mathrm{Si}$ & 2 & 0.42 \\
$p-\mathrm{Ag}_{2} \mathrm{O} / n-\mathrm{PSi} / \mathrm{c}-\mathrm{Si}$ & 2.2 & 0.51 \\
\hline
\end{tabular}

Photovoltaic measurements of $p-\mathrm{Ag}_{2} \mathrm{O} / \mathrm{p}-\mathrm{Si}, \mathrm{p}-\mathrm{Ag}_{2} \mathrm{O} / \mathrm{n}-\mathrm{Si}$, p-Ag $g_{2} \mathrm{O} / \mathrm{p}$-PSi/c-Si and $p-\mathrm{Ag}_{2} \mathrm{O} / \mathrm{n}$-PSi/c-Si devices

These measurements represent the most important results since they describe the performance of the device and then include:

Current-voltage characteristics under illumination Figure 16a-f exhibits the photoelectric behavior of the devices under illumination condition. It is understood that photoelectric effect results from light-induced electronhole generation at the device and particularly at the depletion region of the $n$ - and $p$-type for silicon and porous silicon. Under external reverse bias, depletion region of the device extends and as a result, more incident photons will contribute to the electron-hole pairs generation that takes place in the depletion region. The internal electric filed in the depletion region causes the electron-hole pairs to be separated from each other and this bias becomes large with the applied external bias. From the following figure, we can see the increase in the photocurrent with the increasing incident light intensity, where the large intensity refers to a great number of incident photons and hence large of separated electron-hole pairs.

From this result, enhancement is noticed in values of the photocurrent in $p-\mathrm{Ag}_{2} \mathrm{O} / p$-PSi/c-Si and $p-\mathrm{Ag}_{2} \mathrm{O} / n-\mathrm{PSi} / \mathrm{c}-\mathrm{Si}$ devices comparing with $p-\mathrm{Ag}_{2} \mathrm{O} / p-\mathrm{Si}$ and $p-\mathrm{Ag}_{2} \mathrm{O} / n-\mathrm{Si}$ devices at the same incident light intensity due to the increased width of the depletion layer $(W)$, leading to a higher photocurrent. It is observed in this figure that the current density under illumination from the $n$-Si layer is of almost the same order of magnitude as that of the $n$-PSi layer. This suggests that the $n$-PSi layer should have a very similar $E_{\mathrm{g}}$ value to that of the $n-\mathrm{Si}$ substrate $\left(E_{\mathrm{g}} n-\mathrm{PSi}=E_{\mathrm{g}} n-\mathrm{Si}\right)$ with a same rectifying value between two layers. On the other hand, $p-\mathrm{Ag}_{2} \mathrm{O} / p-\mathrm{Si}$ and $p-\mathrm{Ag}_{2} \mathrm{O} / p-\mathrm{PSi} / \mathrm{c}-\mathrm{Si}$ devices behave quite different because of the difference between the magnitude of the $E_{\mathrm{g}}$ for $p$-Si and $E_{\mathrm{g}}$ for $p$-PSi substrate $\left(E_{\mathrm{g}} p\right.$-PSi $\neq$ $E_{\mathrm{g}} p-\mathrm{Si}$ ), and the rectifying of the $p$-PSi layer is greater than that of the $p-\mathrm{Ag}_{2} \mathrm{O} / p$-PSi device without porous silicon (because the increasing in optical absorption region in the PSi substrate), and this is smaller to the work (Arenas et al. 2008).

\section{Capacitance-voltage measurements}

$C-V$ characteristics of the heterojunction prepared were measured using a PM6306 programmable LRC meter supplied by Fluke under a reverse bias voltage (0.1-1.2 V). The cross point $\left(1 / C^{2}=0\right)$ of the $\left(1 / C^{2}-V\right)$ curve representing the built-in potential of the heterojunction, the charge-carrier density $\left(N_{\mathrm{d}}\right)$ and width of the depletion layer for both devices are calculated by the following equations (Alferov 1989):

$N_{\mathrm{d}}=\frac{2}{q \varepsilon_{\mathrm{s}}}\left[1 / d\left(1 / C^{2}\right) / \mathrm{d} V\right]$

$w=\sqrt{\frac{2 \varepsilon_{\mathrm{s}} V_{\mathrm{bi}}}{q N_{\mathrm{d}}}}$

It is one of the most important measurements since it determines different parameters such as built-in potential, device capacitance and device type.

Figure $17 \mathrm{a}$ and $\mathrm{b}$ gives the $C-V$ and $1 / C^{2}-\mathrm{V}$ measurements for all devices, respectively. Results show that the device capacitance is inversely proportional to the bias voltage. The reduction in the device capacitance with bias voltage resulted from the expansion of depletion layer with the built-in potential. The depletion layer capacitance refers to the increment in-charge per unit area to the increment change of the applied voltage. This properly gives an indication of the behavior of the charge transition from the donor to the acceptor region, which was found to be "abrupt" which is confirmed by the relation between $1 / C^{2}$ and reverse bias being a straight line. The potential barrier at the junction can be measured by small-single capacitance-voltage characteristic; since band bending is primarily on the Si side, the intercept of the curve on the $x$ axis is essentially equal the diffusion potential within the silicon and it value is expected to depend on the Fermi level position in the conduction band at high carrier concentrations. The slope of the straight line gives the donor concentration, in which value corresponds well with the known resistivity of silicon substrate. The built in potential $\left(V_{\mathrm{bi}}\right)$, the width of the depletion layer $(W)$ and the bulk Fermi level of both silicon substrates are calculated and tabulated in Table 4.

The current-voltage characteristics of the solar cells were examined under $100 \mathrm{~mW} / \mathrm{cm}^{2}$ illumination. The relationship between Isc and Voc as a function of load resistance could be recognize in Fig. 18. The efficiency of the device has been measured in six cases: $p-\mathrm{Ag}_{2} \mathrm{O} / p-\mathrm{Si}$, $p-\mathrm{Ag}_{2} \mathrm{O} / n-\mathrm{Si}, \mathrm{Al} / p-\mathrm{PSi} / \mathrm{Al}, \mathrm{Al} / n-\mathrm{PSi} / \mathrm{Al}, p-\mathrm{Ag}_{2} \mathrm{O} / p-\mathrm{PSi} / \mathrm{c}-\mathrm{Si}$ and $p-\mathrm{Ag}_{2} \mathrm{O} / n-\mathrm{PSi} / \mathrm{c}-\mathrm{Si}$ for comparison. Its value found to be $3.64,1.88,6.23,5.06,8.58$ and 7.75 , respectively. The improvement in value of quantum efficiency $(\mathrm{QE})$ in the $p-\mathrm{Ag}_{2} \mathrm{O} / p-\mathrm{Si}, \mathrm{Al} / p-\mathrm{PSi} / \mathrm{Al}$ and $p-\mathrm{Ag}_{2} \mathrm{O} / p-\mathrm{PSi} / \mathrm{c}-\mathrm{Si}$ cases is 


\section{(a) Reverses Voltage (Volt)}

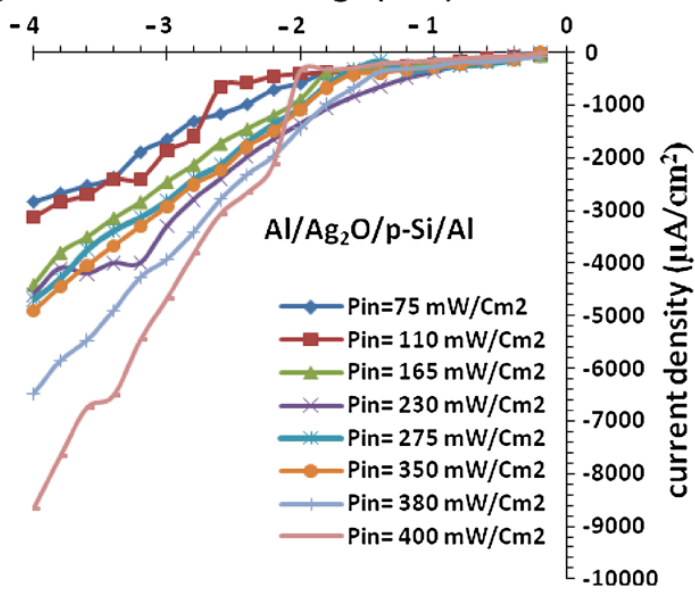

(c) Reverses Voltage (Volt)

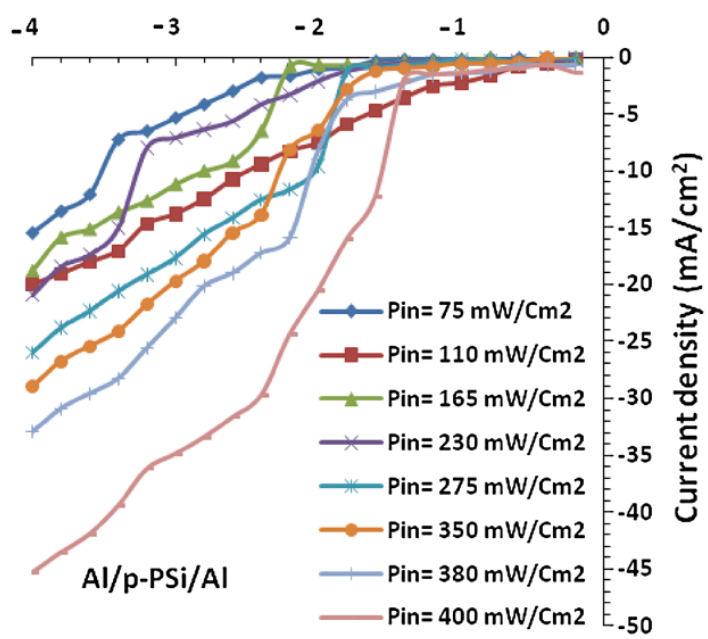

(e) Reverses Voltage (Volt)

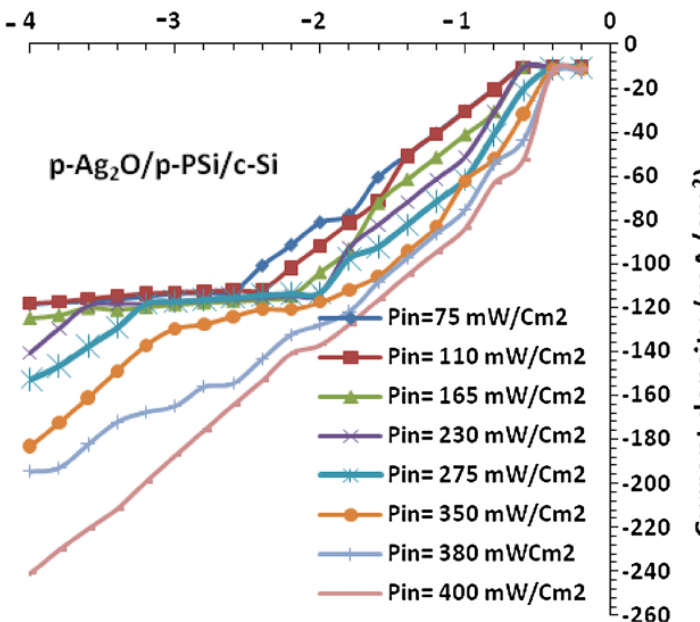

(b) Reverses Voltage (Volt)

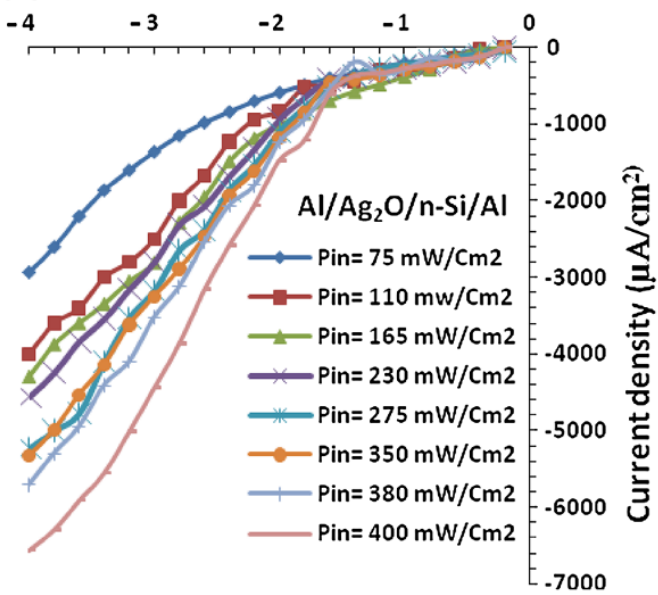

(d) Reverses Voltage (Volt)

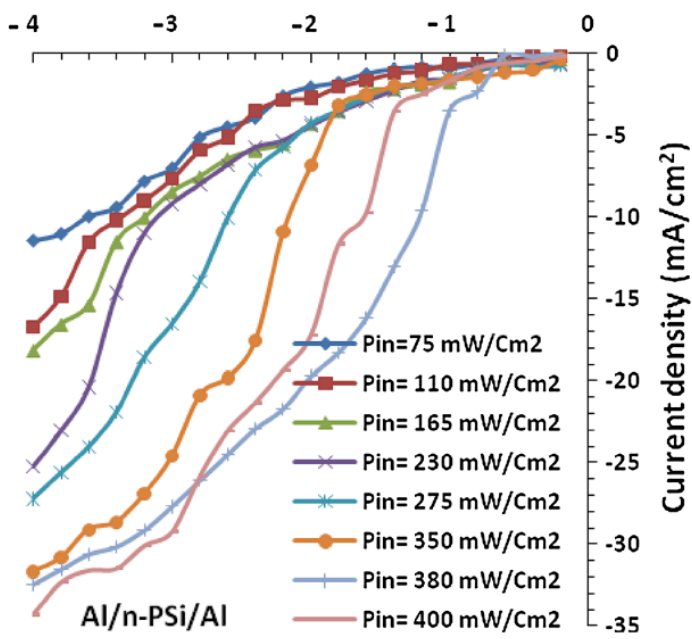

(f) Reverses Voltage (Volt)

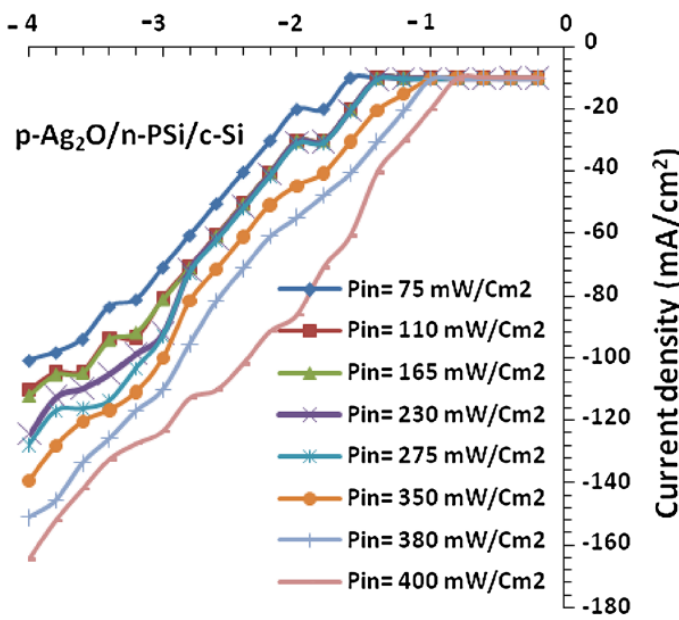

Fig. 16 Photo-current density as a function of the reverse voltage at different values of incident light power density. a $p-\mathrm{Ag}_{2} \mathrm{O} / p-\mathrm{Si}, \mathbf{b} p-\mathrm{Ag}_{2} \mathrm{O} /$ $n$-Si, c $\mathrm{Al} / p$-PSi/Al, d Al $/ n$-PSi $/ \mathrm{Al}$, e $p-\mathrm{Ag}_{2} \mathrm{O} / p$-PSi $/ c-S i$ and $\mathbf{f} p-\mathrm{Ag}_{2} \mathrm{O} / n$-PSi $/ c-S i$ devices 
Fig. 17 a Junction capacitance as a function of applied voltage, b $1 / C^{2}$ vs. applied voltage for $p-\mathrm{Ag}_{2} \mathrm{O} / n-\mathrm{Si}, p-\mathrm{Ag}_{2} \mathrm{O} / p-\mathrm{Si}$, $p-\mathrm{Ag}_{2} \mathrm{O} / n$-Psi, $p-\mathrm{Ag}_{2} \mathrm{O} / p$-Psi devices (a)

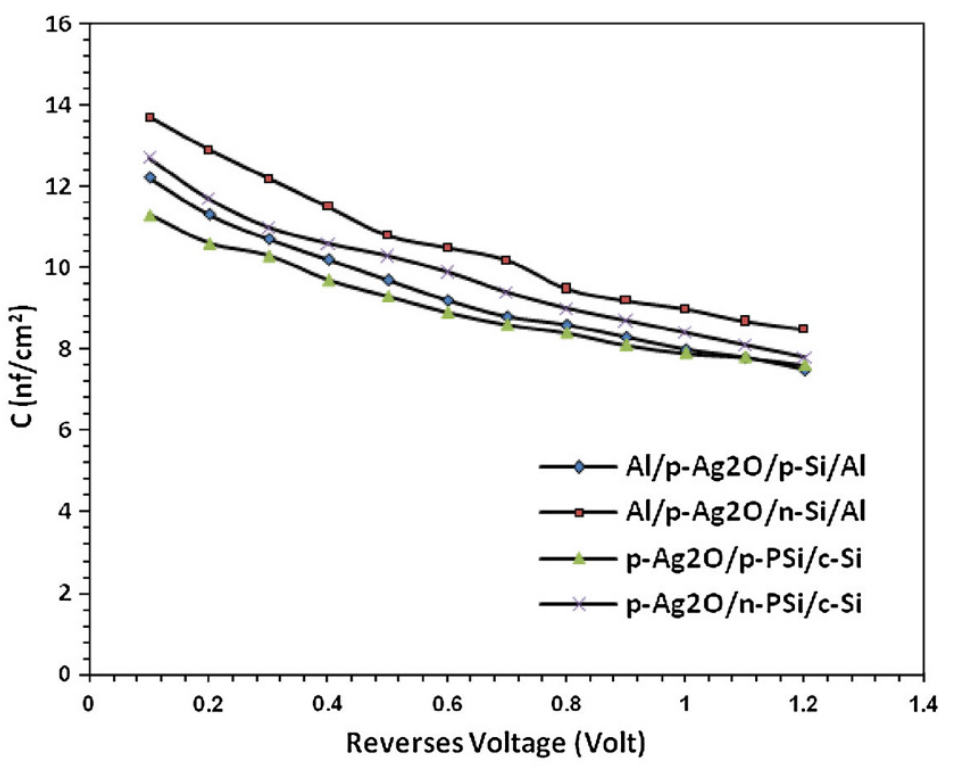

(b)

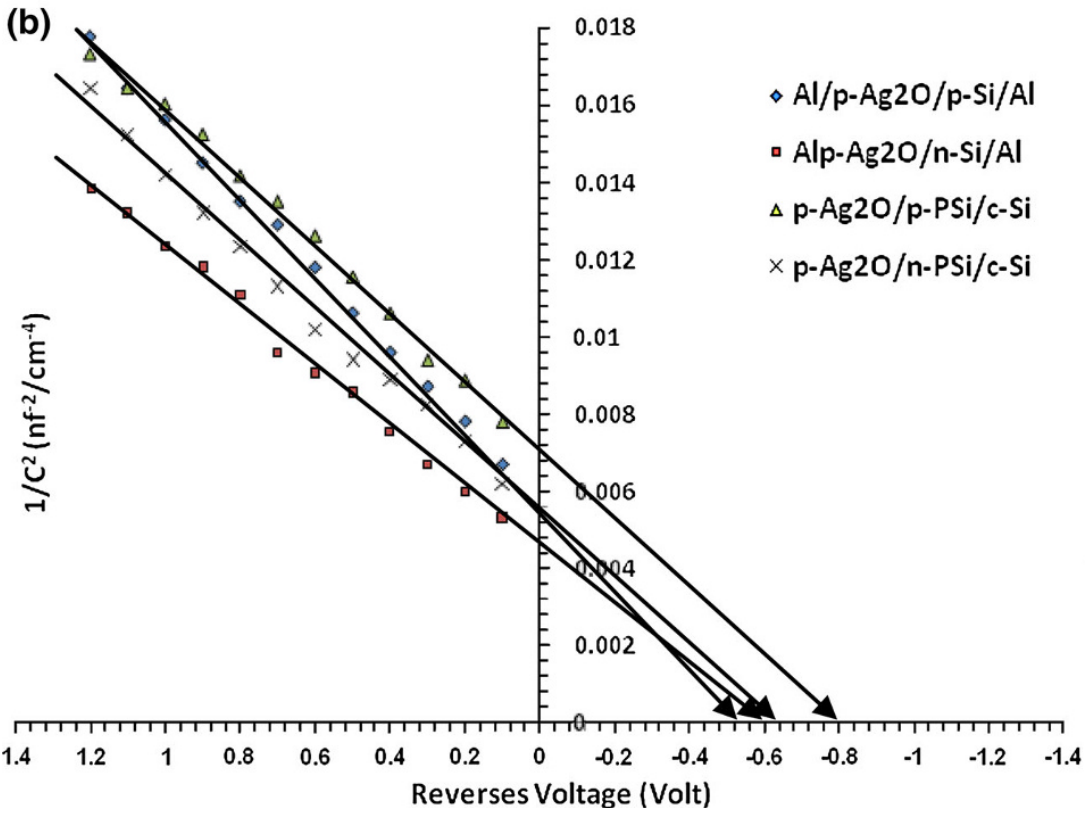

Table 4 The obtained results from the $C-V$ measurements

\begin{tabular}{llllll}
\hline Device & $V_{\text {bi }}(\mathrm{V})$ & $N_{\mathrm{d}}\left(\mathrm{cm}^{-3}\right)$ & $W(\mu \mathrm{m})$ & $C\left(\mathrm{nF} / \mathrm{cm}^{2}\right)$ & $E_{\mathrm{c}}-E_{\mathrm{f}}(\mathrm{eV})$ \\
\hline$p-\mathrm{Ag}_{2} \mathrm{O} / p-\mathrm{Si}$ & 0.57 & $1.4 \times 10^{15}$ & 0.66 & 13.4 & 0.247 \\
$p-\mathrm{Ag}_{2} \mathrm{O} / n-\mathrm{Si}$ & 0.6 & $1.7 \times 10^{15}$ & 0.61 & 14.5 & 0.242 \\
$p-\mathrm{Ag}_{2} \mathrm{O} / p-\mathrm{PSi} / \mathrm{c}-\mathrm{Si}$ & 0.8 & $1.6 \times 10^{15}$ & 0.74 & 11.9 & 0.244 \\
$p-\mathrm{Ag}_{2} \mathrm{O} / n-\mathrm{PSi} / \mathrm{c}-\mathrm{Si}$ & 0.65 & $1.5 \times 10^{15}$ & 0.69 & 12.8 & 0.245 \\
\hline
\end{tabular}

related to the reflection of light rays from one side inside the key hall surface merely to strike another, resulting in an improved probability of absorption, and therefore reduced reflection comparing to the crystalline silicon surface (Ismail and March 2009). Also, due to the absorption phenomena in the surface oxide layer and at the $p-\mathrm{Ag}_{2} \mathrm{O}$ /
$p$-Si, $\mathrm{Al} / p-\mathrm{PSi} / \mathrm{Al}$ and $p-\mathrm{Ag}_{2} \mathrm{O} / p-\mathrm{PSi} / \mathrm{c}-\mathrm{Si}$ junction that formed between $\mathrm{Ag}_{2} \mathrm{O}$ nanostructure thin film and porous silicon, beside that, the interfacial porous silicon oxide $\left(\mathrm{PSiO}_{2}\right)$ layer between porous silicon (PSi) itself and metal oxide $\mathrm{Ag}_{2} \mathrm{O}$ plays a significant role in enhancing the properties, since it has been found that the porous silicon 

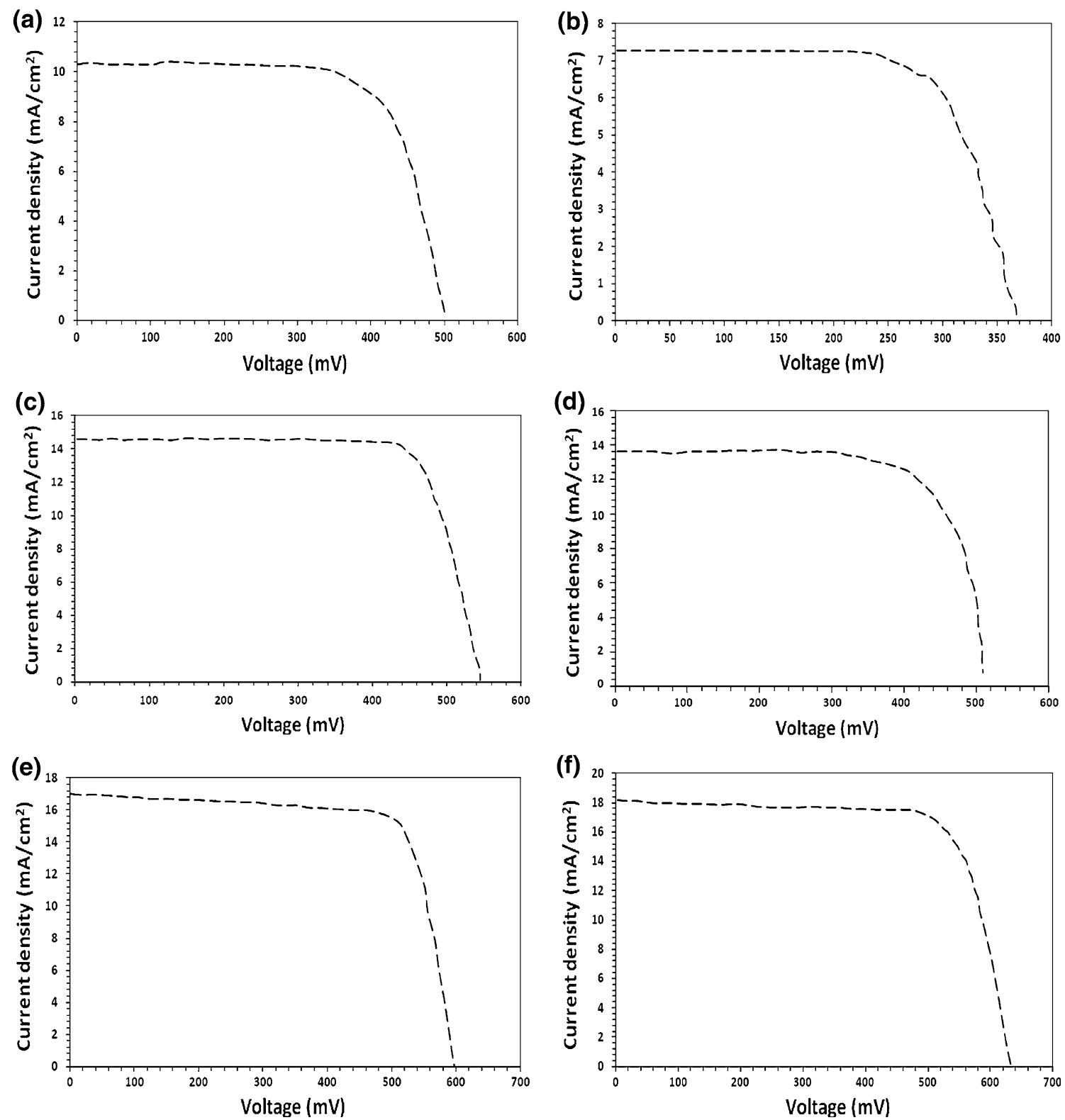

Fig. $18 I-V$ characteristics of solar cells. a $p-\mathrm{Ag}_{2} \mathrm{O} / p-\mathrm{Si}, \mathbf{b} p-\mathrm{Ag}_{2} \mathrm{O} / n-\mathrm{Si}, \mathbf{c} \mathrm{Al} / p-\mathrm{PSi} / \mathrm{Al}, \mathbf{d ~} \mathrm{Al} / n-\mathrm{PSi} / \mathrm{Al}, \mathbf{e} p-\mathrm{Ag}_{2} \mathrm{O} / p-\mathrm{PSi} / \mathrm{c}-\mathrm{Si}$ and $\mathbf{f} p-\mathrm{Ag}{ }_{2} \mathrm{O} / n-\mathrm{PSi} /$ c-Si devices

Table 5 The obtained results from the solar cell

\begin{tabular}{lclllll}
\hline Solar cells & $I_{\mathrm{m}}(\mathrm{mA})$ & $V_{\mathrm{m}}(\mathrm{mV})$ & $I_{\mathrm{sc}}(\mathrm{mA})$ & $V_{\mathrm{oc}}(\mathrm{mV})$ & $\mathrm{FF} \%$ & $\eta \%$ \\
\hline$p-\mathrm{Ag}_{2} \mathrm{O} / p-\mathrm{Si}$ & 9.04 & 403.75 & 10.29 & 501.2 & 70.77 & 3.64 \\
$p-\mathrm{Ag}_{2} \mathrm{O} / n-\mathrm{Si}$ & 6.53 & 288.75 & 7.28 & 367.5 & 70.47 & 1.88 \\
$\mathrm{Al} / p-\mathrm{PSi} / \mathrm{Al}$ & 14.29 & 436.25 & 14.61 & 545 & 78.29 & 6.23 \\
$\mathrm{Al} / n-\mathrm{PSi} / \mathrm{Al}$ & 12.44 & 407.50 & 13.64 & 508.7 & 73.05 & 5.06 \\
$p-\mathrm{Ag}_{2} \mathrm{O} / p-\mathrm{PSi} / \mathrm{c}-\mathrm{Si}$ & 16.95 & 506.25 & 18.15 & 632.5 & 74.74 & 8.58 \\
$p-\mathrm{Ag}_{2} \mathrm{O} / n-\mathrm{PSi} / \mathrm{c}-\mathrm{Si}$ & 15.11 & 513.75 & 16.99 & 597.5 & 76.46 & 7.75 \\
\hline
\end{tabular}

could be oxidized at high temperatures forming an porous oxide layer. Heating of porous silicon to high temperature in a strong oxidation ambient leads to vary rapid oxidation of the structure. Rapid thermal oxidation of porous silicon makes it suitable as dielectric layer for any electronic device. Most of its applications involve the formation of 
stable $\mathrm{SiO}_{2}$ layers obtained by a simple technological process like thermal oxidation of porous $\mathrm{Si}$ at high temperature which is conveniently carried out by the use of RTO; involving transient heat of oxygen ambient, careful control of the potential rapid surface reaction can be maintained. The results (Table 5) also show the conversion efficiency and fill factor (FF) of the solar cell using the following equation (Salman et al. 2012):

$\eta=\frac{P_{\mathrm{m}}}{P_{\mathrm{i}}}=\frac{I_{\mathrm{m}} V_{\mathrm{m}}}{P_{\mathrm{i}}}$

where $P_{\mathrm{m}}$ and $P_{\mathrm{i}}$ are the output and incident powers, respectively. The FF was calculated by Eq. (11) (Salman et al. 2012):

$\mathrm{FF}=\frac{I_{\mathrm{m}} V_{\mathrm{m}}}{I_{\mathrm{SC}} V_{\mathrm{OC}}}$

\section{Conclusions}

The structural properties of undoped polycrystalline $\mathrm{Ag}_{2} \mathrm{O}$ thin film prepared at different film thickness using rapid thermal oxidation technique and their application to $p-\mathrm{Ag}_{2} \mathrm{O} / p-\mathrm{Si}, \quad p-\mathrm{Ag}_{2} \mathrm{O} / n-\mathrm{Si}, \quad \mathrm{Al} / n-\mathrm{PSi} / \mathrm{Al}, \quad \mathrm{Al} / p-\mathrm{PSi} / \mathrm{Al}$, $p-\mathrm{Ag}_{2} \mathrm{O} / p-\mathrm{PSi} / \mathrm{c}-\mathrm{Si}$ and $p-\mathrm{Ag}_{2} \mathrm{O} / n-\mathrm{PSi} / \mathrm{c}-\mathrm{Si}$ heterojunction optoelectronic were examined. The technique of growing $\mathrm{Ag}_{2} \mathrm{O}$ layer by rapid photothermal oxidation for optoelectronic devices is relatively new, simple, cheap and reliable. We are in the process of improving the performance of photodetector by post-oxidation annealing of $\mathrm{Ag}_{2} \mathrm{O}$ and/or by deposition of buffer layer.

Open Access This article is distributed under the terms of the Creative Commons Attribution License which permits any use, distribution, and reproduction in any medium, provided the original author(s) and the source are credited.

\section{References}

Alferov IZh (1989) Semiconductor heterostructures physical processes and applications. Printed in RSSA

Al-Hardan N, Abdulllah M (2009) The gas response enhancement from $\mathrm{ZnO}$ film for $\mathrm{H}_{2}$ gas detection. Appl Surf Sci 255:7749

Arenas MC, Hu H, Scanchez A (2006) Sol Energy Mater Sol Cells 90:2431

Arenas MC, $\mathrm{Hu} \mathrm{H}$, Antonio $\mathrm{J}$ (2008) Photovoltage and $J-V$ features of porous silicon. Rev Mex Fis 54:391-396

Büchel D, Mihalcea C, Fukaya T, Atoda N, Tominaga J, Kikukawa T, Fuji H (2001) Appl Phys Lett 79:620

Ben-Chorin M, Schechter I, Kux A (1995) Gas sensing properties of porous silicon. Anal Chem 67(20):3727-3732

Berger S, Quoizla S, Fave A, Ouldabbes A, Kaminski A, Perichon S, Sari NE, Barbier D, Laugier A (2001) Cryst Res Technol 36:1005

Bisi O, Ossicini S, Pavesi L (2002) Surf Sci Rep 38:1

Cai DP, Wei CL (2000) Appl Phys Lett 77:1413
Canha L (1993) New Scientist 1868

Canham L (1997a) Properties of porous silicon. Institution of Engineering and Technology, UK

Canham LT (1997b) Storage of porous silicon. In: Canham L (ed) Properties of porous silicon. INSPEC, London, pp 44-50

Canham LT, Houlton MR, Leong WY, Pickering C, Keen JM (1991) Atmospheric impregnation of porous silicon at room temperature. J Appl Phys 70(1):422-431

Chan S (2000) Porous silicon multilayer structures. Thesis, University of Rochester, New York

Chen C-W, Hsieh P-Y, Chiang H-H, Lin C-L, Wu H-M, Wua C-C (2003) Appl Phys Lett 83:25

Chiu Y, Rambabu U, Hsu MH, Shieh HPD, Chen CY, Lin HH (2003) J Appl Phys 94:1996

Feng Z, Tsu R (1994) Porous silicon. World Scientific, London

Foss SE (2005) Graded optical filters in porous silicon for use in MOEMS applications. PhD Thesis, University of Oslo, Oslo, Norway

Fuji H, Tominaga J, Men L, Nakano T, Katayama H, Atoda N (2000) Jpn J Appl Phys 39:980

Fukaya T, Tominaga J, Nakano T, Atoda N (1999) Appl Phys Lett 75:3114

Gaburro Z, Bellutti P, Chierchia R, Mulloni V, Pavesi L (2000) Mater Sci Eng B 69-70:109

Guerrero-Lemus R, MartõÂn-Palma RJ, Moreno JD, MartõÂnezDuart JM (1999) Determination of the spectral behaviour of porous silicon based photodiodes. Solid State Electr 43(1153): 1157

Gyogy E, Axente E (2000) Doped thin metal oxide films for catalytic gas sensors. Appl Surf Sci 2030:4123

Hou SM, Ouyang M, Chen HF, Liu WM, Xue ZQ, Wu QD, Zhang HX, Gao HJ, Pang SJ (1998) Thin Solid Films 315:322

Ismail RA (2009) J Semiconductor Technol Sci 9(1)

Kaidashev E, Lorenz M, Von H, Rahm A, Semmelhack H (2003) High electron mobility of epitaxial $\mathrm{TiO}_{2}$ thin films on C-plane sapphire grown by multistep pulsed-laser deposition. Appl Phys Lett 82:3901

Kasap S (2002) Principles of electronic materials and devices, 2nd edn. McGraw Hill, New York, p 557

Kim J, Fuji H, Yamakama Y, Nakano T, Buchel D, Tominaga J, Atoda N (2001) Jpn J Appl Phys 40:1634

Kocka J, Fejfar A, Pelant I (1995) Phys Stat Solid B 190:27

Lehmann V (1993) J Electrochem Soc 140:2836

Lugo J, del Rio J (1998) Sol Energy Mater Sol Cells 52:239

Muller RS, Anderson RC, Tobias CW (1991) Investigation of the electrical properties of porous silicon. J Electrochem Soc 138(11):3406-3411

Pascual A, Fernandez JF, Sanchez CR (2002) J Appl Phys 92:866

Passaniti J, Megahed SA (1995) Handbook of batteries. McGraw-Hill, New York, p 122

Peyser LA, Vinson AE, Bartko AP, Dickson RM (2001) Science 291:103-106

Ravi Chandra Raju N (2011) Department of Physics Indian Institute of Technology, Madras

Sagnes L, Halimaoui A, Vincen G (1993) Appl Phys Lett 62:1155

Salman KA, Hassan Z, Omar K (2012) Int J Electrochem Sci 7:376-386

Shih J, Yan S, Jung KH, Kwong DL (1993) Study of thermal oxygen and nitrogen annealing of luminescent porous silicon. Appl Phys 64:1348-1350

Smestad G, Kunst M (1992) Energy Mater Sol Cells 26:227

Smith DF, Graybill GR, Grubbs RK, Gucinskl JA (1997) J Power Sources 65:47

Song D, Zhao J, Wang A, Widenborg P, Chin W, Aberle AG (2001) 17th European PV Conference, Munich, p 1

Tominaga J (2003) J Phys Condens Mat 15:R1101 
Tominaga J, Nakano T, Atoda N (1992) Extended abstracts of the 39th spring meeting of the japan society of applied physics and related societies (Narashino), p 30

Tominaga J, Nakano T, Atoda N (1998) Appl Phys Lett 73:2078

Van T, Dinh L (1998) Changes in the electronic properties of silicon nanocrystals as a function of particle size. Phys Rev Lett 80(17):27
Vial JC, Derrien J (1995) Porous silicon and technology. Springer, New York

Zhang XY, Pan XY, Zhang QF, Xu BX, Jiang HB, Liu CL, Gong QH, Wu JL (2003) Acta Phys Chim Sin 19:203 